\title{
CLIMATE AND CONFLICT
}

\author{
Marshall Burke \\ Solomon M. Hsiang \\ Edward Miguel \\ Working Paper 20598 \\ http://www.nber.org/papers/w20598
NATIONAL BUREAU OF ECONOMIC RESEARCH
1050 Massachusetts Avenue
Cambridge, MA 02138
October 2014

Forthcoming in the Annual Review of Economics, Doi: 10.1146/annurev-economics-080614-115430. We thank Tamma Carleton for outstanding research assistance. The views expressed herein are those of the authors and do not necessarily reflect the views of the National Bureau of Economic Research.

NBER working papers are circulated for discussion and comment purposes. They have not been peerreviewed or been subject to the review by the NBER Board of Directors that accompanies official NBER publications.

(C) 2014 by Marshall Burke, Solomon M. Hsiang, and Edward Miguel. All rights reserved. Short sections of text, not to exceed two paragraphs, may be quoted without explicit permission provided that full credit, including $\odot$ notice, is given to the source. 
Climate and Conflict

Marshall Burke, Solomon M. Hsiang, and Edward Miguel

NBER Working Paper No. 20598

October 2014

JEL No. I3,O1,P48,Q51,Q54

\begin{abstract}
Until recently, neither climate nor conflict have been core areas of inquiry within economics, but there has been an explosion of research on both topics in the past decade, with a particularly large bodylof research emerging at their intersection. In this review, we survey this literature on the interlinkages between climate and conflict, by necessity drawing from both economics and other disciplines given the inherent interdisciplinarity of research in this field. We consider many types of human conflict in the review, including both interpersonal conflict - such as domestic violence, road rage, assault, murder, and rape - and intergroup conflict - including riots, ethnic violence, land invasions, gang $\backslash$ violence, civil war and other forms of political instability, such as coups. We discuss the key methodologicallissues in estimating causal relationships in this area, and largely focus on "natural experiments" that lexploit variation in climate variables over time, helping to address omitted variable bias concerns. ¿After harmonizing statistical specifications and standardizing estimated effect sizes within each conflict\category, we carry out a hierarchical meta-analysis that allows us to estimate the mean effect of climate|variation on conflict outcomes as well as to quantify the degree of variability in this effect size across $₫$ studies. Looking across 55 studies, we find that deviations from moderate temperatures and precipitation[patterns systematically increase the risk of conflict, often substantially, with average effects that are highly statistically significant. We find that contemporaneous temperature has the largest average effect by far, with each $1 \sigma$ increase toward warmer temperatures increasing the frequency of contemporaneous interpersonal conflict by $2.4 \%$ and of intergroup conflict by $11.3 \%$, but that the 2-period cumulative effect of rainfall on intergroup conflict is also substantial $(3.5 \% / \sigma)$. We also quantify heterogeneity in these effect estimates across settings that is likely important. We conclude by highlighting remaining challenges in this field and the approaches we expect will be most effective at solving them, including identifying mechanisms that link climate to conflict, measuring the ability of societies to adapt to climate changes, and understanding the likely impacts of future global warming.
\end{abstract}

Marshall Burke

Center on Food Security and Environment

Stanford University

Stanford CA 94305

mburke@stanford.edu

Solomon M. Hsiang

Goldman School of Public Policy

University of California, Berkeley

2607 Hearst Avenue

Berkeley, CA 94720-7320

and NBER

shsiang@berkeley.edu
Edward Miguel

Department of Economics

University of California, Berkeley

530 Evans Hall \#3880

Berkeley, CA 94720

and NBER

emiguel@econ.berkeley.edu 


\section{Introduction}

The goal of this article is to survey and synthesize the rapidly expanding econometric literature that studies the links between climate and conflict. Until the past decade, neither climate nor conflict have been core areas of inquiry within economics as a whole, and the same holds even for development economics, where their study is arguably most natural. As recently as 2007, when one of the authors carried out a survey of sixty-three development economics course syllabi (at both the undergraduate and graduate levels) in leading U.S. universities, only a handful of courses mentioned either conflict or climate, and leading development economics textbooks did not contain these words in their subject index. ${ }^{1}$ However, both of these topics have moved center stage over the past decade and are now widely taught and researched within economics and throughout the broader social science research community. This shift is at least partly a result of greater popular awareness of the critical role that climate might play in driving economic outcomes, and in particular rising public concern about climate change. Similarly, the violent aftermath of the Arab Spring revolutions, and the broader fact that conflict remains widespread in most low and middle income regions, have made it clear to many observers that economic development, political change and violent conflict are inextricably linked, and that armed conflict is not going away any time soon.

In this paper, we focus on over 50 quantitative papers that examine the link between climate and conflict using modern econometric methods that make credible attempts to draw causal inferences from data. Illustrating just how new research interest on these topics is within economics, the median year of publication among the studies we consider is 2012 . While the quantitative literature on this topic is very recent, researchers working in other disciplines including archaeology, criminology, geography, history, political science, and psychology - have long debated the extent to which climatic changes are responsible for conflict, violence or political instability (see for example, Huntington (1917); Levy (1995); Homer-Dixon (1999); Anderson et al. (2000); Davis (2001); DeMenocal (2001); Kuper and Kröpelin (2006); Grove (2007); Scheffran et al. (2012); Gleditsch (2012)), and historians have connected prolonged periods of extreme climate with the collapse of major human civilizations (see Buckley et al. (2010); Cullen et al. (2000); Diamond (2005); Fagan (2000); Haug et al. (2003); Yancheva et al. (2007)). Numerous pathways linking the climate to these outcomes have been proposed. For example, climatic changes may alter the supply of natural resources and lead to disagreement over their allocation, or climatic conditions may shape the relative appeal of using violence versus cooperation to achieve an objective. Now, improvements in data availability, computing, and statistical methods have prompted an explosion of quantitative analyses seeking to test these theories and quantify the strength of these previously proposed linkages. A central goal of this piece is to make sense of this diverse and growing body of literature, and to chart a productive path forward for future research.

In this article, we use the terms climate and conflict and to describe broad classes of variables, and it is worth clarifying our use of these key terms up front.

\footnotetext{
${ }^{1}$ See Blattman and Miguel (2010) for details on the survey.
} 
Climate We use climate to refer to observations of climatic variables: temperature, rainfall, and water availability, as well as climate indices that proxy for these measures, such the El Niño-Southern Oscillation index or the Palmer Drought Severity Index. These variables may be averaged over longer or shorter observational periods. Some authors argue that short averaging periods (e.g., annual) only describe the "weather" or "climate variability" and thus have little to say about the impact of "climate." We do not agree with this view. Societies experience climatic variables in continuous time and respond to both short-lived and long-term changes, making the frequency of short-lived events an economically-relevant feature of the climate. For example, if hot temperatures increase the likelihood of riots in a city - even if hot temperatures are only experienced for a few hours - then this is important for understanding climate impacts because the frequency of these momentary events may change if the distribution of daily temperatures changes.

Conflict We use the term conflict to describe events where regular patterns of dispute resolution fail. These events are usually violent in nature (although they need not be in all cases), they may involve individuals or groups, they may be organized or disorganized, and they may be personally, politically or otherwise motivated. While most existing empirical studies examine only one type of conflict at a time, in this review we examine this comprehensive set of outcomes because different types of conflict are potentially related and that their responses to climate might exhibit some commonalities. Our hope is that evaluating these phenomena together might help us better understand each individually.

The rest of this article is organized as follows. Secton 2 presents the existing evidence linking climate to conflict, and is the core of the paper. We begin the section by discussing the key methodological issues in estimating causal relationships in this area, and then survey the existing evidence across different types of conflict with particular attention to those studies capable of making credible causal claims. After collecting and standardizing estimated effect sizes across papers, we carry out a hierarchical Bayesian meta-analysis that both allows us to estimate the mean effect of climate variation on conflict outcomes and also quantifies the degree of variability in this effect size across studies. Section 3 lays out the leading theoretical mechanisms linking extreme conflict to conflict - including both economic theories and non-economic explanations, such as those from psychology - evaluates the limited body of empirical evidence regarding the importance of these channels and recommends methods for identifying causal pathways in future work. Section 4 discusses remaining challenges in this field, including data limitations, the challenge of understanding whether societies effectively adapt to climatic conditions, and the need to better understand the likely impacts of future global climate change. Section 5 concludes. 


\section{Evidence linking climate to conflict}

Climatic conditions never cause conflict alone, but changes in climate can alter the conditions under which certain social interactions occur and thus have the potential to change the likelihood that conflict results. The situation is similar to the rise in car accident rates during rainy days. Car accidents themselves are almost always due to some form of driver or mechanical error; however, heavy rainfall may increase the probability of a critical error or the risk that a small error has cascading effects that in turn generate a crash (perhaps the car begins to fishtail, setting off a multi-car accident). Without the possibility of driver or mechanical errors, rainfall would have no effect on car accident rates, but without rainfall, there would still be some accidents. Similarly, climatic conditions are neither necessary nor sufficient for conflicts to occur, but changes in climatic conditions could have measurable impact on the probability and intensity of conflict, holding other conflict-related factors fixed. The central empirical challenge addressed by the literature to date has been to quantify this effect.

\subsection{The Empirical Problem}

In an ideal experiment, we would observe two identical populations or societies, change the climate of one, and observe whether this "treatment" leads to more or less conflict relative to the "control" conditions. Because the climate cannot (yet) be experimentally manipulated, research has relied on natural experiments where plausibly exogenous variation in climatic variables generates changes in conflict risk that can be measured by an econometrician. The central challenge in this context is to identify plausibly homogenous populations, only some of which are naturally treated with a climatic event, that one can reasonably believe would behave similarly had neither been subject to a climate treatment (Freedman (1991); Holland (1986)).

\subsubsection{Cross-sectional approaches}

One approach to the above problem would be to assume that populations or societies inhabiting different locations are identical to one another in all respects except their climate, usually after regression adjustment for observable economic, social and political correlates of conflict. For example, Buhaug (2010a) compares the rate of civil war across different countries in Africa. It seems implausible that the conditions needed for causal inference are met in this setting: there are many ways in which populations and societies differ from one another (i.e., culture, history, etc.), many of them unobserved or hard to measure, so we cannot infer whether a climatic "treatment" has a causal effect or not (Angrist and Pischke (2008); Wooldridge (2002)). In the above example, the cross-sectional analysis by Buhaug (2010a) compares average rates of civil conflict in South Africa and Nigeria (among many comparisons), attributing observed differences to the different climates of these countries - despite the fact that there are many other relevant ways in which these countries differ. Hsiang and Meng (2014) revisit this example and explicitly test the assumption that no important omitted variables are missing from the analysis. Perhaps unsurprisingly, they strongly reject the assumption that baseline conflict rates in these countries are comparable, suggesting that they are unlikely to be valid counterfactuals for one another. 
We take the critique by Hsiang and Meng (2014) seriously and argue that in general, the handful of covariates such as national per capita income or political indices that are commonly used in cross-sectional regression analyses are insufficient to credibly account for the numerous ways in which populations and societies differ from one another. Because the full suite of determinants of conflict are unknown and unmeasured, it is likely impossible that any cross-sectional study can explicitly account for all important differences. For this reason, we do not draw causal inferences on the relationship between climate and conflict from cross-sectional analyses in this article, and instead rely on panel data approaches.

\subsubsection{Identification in time series}

Rather than presuming that all confounders are accounted for in a cross-sectional regression, the bulk of recent studies estimate the effect of climate on conflict by using time-series variation for identification, usually in a panel data context. In this research design, a single population serves as both the "control" population - e.g. just before a change in climatic conditions- and the "treatment" population - e.g. just after a change in climatic conditions. Inferences are thus based on how a fixed population responds to different climatic conditions which vary over time. Here the assumptions necessary for causal inference are more likely to be met, since the structure, history and geography of comparison populations are nearly identical. Therefore, we follow Hsiang, Burke, and Miguel (2013a) and restrict our attention in this review on studies that use variation over time in a given location to study the climate/conflict relationship.

As pointed out by Hsiang and Burke (2013), the central shortcoming of this approach is the frequency-identification tradeoff that emerges because populations and societies evolve at a much faster rate than many low-frequency climatic changes of interest. For example, if we are interested in the effect of a climate change that takes one hundred years to manifest, then the "control" and "treatment" populations in our sample must necessarily be roughly one hundred years apart on average. However, human populations may change dramatically over one hundred years, violating the assumption that the "control" and "treatment" populations are largely comparable. This generates a direct tension between our ability to credibly identify causal effects of climate and our ability to examine slow-moving climatic changes. Stated generally, for an outcome $Y_{t}$ observed at time $t$, conditional on contemporaneous climatic conditions $C_{t}$, the estimate for the effect of a change after a time interval $\Delta t$ is

$$
\hat{\beta}=\mathrm{E}\left[Y_{t+\Delta t} \mid C_{t+\Delta t}\right]-\mathrm{E}\left[Y_{t} \mid C_{t}\right]
$$

This estimate approaches the true parameter of interest

$$
\beta=\mathrm{E}\left[Y_{t} \mid C_{t+\Delta t}\right]-\mathrm{E}\left[Y_{t} \mid C_{t}\right]
$$

so long as $Y_{t}$ is comparable to $Y_{t+\Delta t}$ conditional on $C$ (and possibly other covariates). This is the identifying assumption of this research design. However, as the frequency $\frac{1}{\Delta t}$ of the climatic variation of interest becomes lower (climate changes become more gradual) $\Delta t$ becomes larger and the assumption that $Y_{t}$ and $Y_{t+\Delta t}$ are comparable becomes increasingly difficult to justify. 
This tradeoff between the temporal frequencies over which climate effects can be identified and those that we may wish to understand is arguably the central drawback of this approach.

\subsection{Econometric specification}

The time-series or panel analyses that we focus on use versions of the general model:

$$
\text { conflict_variable } i t=\beta \times \text { climate_variable }_{i t}+\mu_{i}+\theta_{t}+\epsilon_{i t}
$$

where locations are indexed by $i$, observational periods are indexed by $t, \beta$ is the parameter of interest and $\epsilon$ is the error. This modern panel data approach was first introduced (to the best of our knowledge) to the conflict literature by Miguel, Satyanath, and Sergenti (2004). If different locations in a sample exhibit different average levels of conflict - because of any number of cultural, historical, political, economic, geographic or institutional differences between the locations - this will be accounted for by the location-specific fixed-effects $\mu_{i}$. Time fixed effects $\theta_{t}$ flexibly account for other time-trending variables such as economic growth or gradual demographic changes that could be correlated with both climate and conflict. In some cases in the existing literature, the $\theta_{t}$ parameters may be replaced by a generic trend (eg. $\bar{\theta} \times t$ ) which is possibly nonlinear and is either common to all locations or may be a vector of location-specific trends $\left(\right.$ eg. $\left.\bar{\theta}_{i} \times t\right)$. In many cases, Eq. 3 also includes in the covariates the climate variable of interest lagged, as well as possibly controls for "nuisance" climate variables (e.g. rainfall, if temperature is the variable of interest) that are treated as controls because they may be correlated with the climate variable of interest (Auffhammer et al. (2013)).

We first present conclusions from the literature as initially presented by authors in their preferred regression specification. These models may have different structure imposed on their trends, different climate controls and different lags of climate variables. However, all of them include location-specific fixed-effects since that is central to the credibility of the result, and is the methodological selection criteria we employ for inclusion in this review.

These author-preferred results are useful to highlight because individual authors are likely to have detailed knowledge about the contexts they study, and thus it is reasonable to believe that they would be more likely to choose an appropriate econometric model based on this insight, i.e., recognizing which climate variables are most influential or which time controls are most important. However, differences in authors' econometric modeling approaches present some difficulties when comparing results across studies. It is possible that authors selectively focus on their "strongest" results in terms of coefficient magnitude or statistical significance, introducing bias. For these reasons, we also present a second set of empirical results where we use a single standardized specification including both contemporaneous and lagged terms for all available climate variables. In cases where the authors did not present such a specification in their paper, we obtain the original data wherever possible and re-analyze the results using this approach or we contacted authors and received updated analyses from them in line with our specification. In all, we carried out a re-analysis for 29 studies out of the 56 total studies include in this review. ${ }^{2}$

\footnotetext{
${ }^{2}$ We obtained data and performed re-analysis ourselves on 24 studies, and for 5 other studies the authors were
} 


\subsubsection{Lag structure, displacement, and persistence}

In cases where authors present a distributed-lag model or when we re-analyze a dataset, the general form of the estimation equation is:

$$
\text { conflict_variable }_{i t}=\beta_{0} \times \text { climate_variable }_{i t}+\beta_{1} \times \text { climate_variable }_{i, t-1}+\mu_{i}+\theta_{t}+\epsilon_{i t}
$$

where $\beta_{1}$ is the effect of the prior period's climate $(t-1)$ on conflict in the present period $(t)$, and $\beta_{0}$ is the contemporaneous effect. $\beta_{1}$ might be nonzero for three reasons. First, climatic events might induce conflicts to be displaced in time, for instance delaying a conflict that will eventually occur anyway or accelerating the emergence of a conflict that would have otherwise occurred in the future. In either case, $\beta_{0}$ and $\beta_{1}$ would have opposite signs but be equal in magnitude, and the net effect of climatic event - the sum of $\beta_{0}$ and $\beta_{1}$ - would be zero. If there is an increase in the number of contemporaneous conflicts in addition to a displacement of conflicts forward in time (i.e. partial displacement), then the lagged effect will be negative but the cumulative effect will remain positive (Hsiang, Burke, and Miguel (2014)). In the presence of either full or partial displacement, estimating (3) instead of (4) will overstate the effect of climate on conflict.

However, it is also possible that climate events could have persistent or delayed effects on conflict. Suppose that conflicts in rural regions are more likely when agricultural productivity is low (an oft-cited mechanism, discussed in detail below). Because agricultural growing seasons are long and often span calendar years, a climatic event early in the growing season might affect the harvest in the next calendar year, which could result in a zero coefficient on $\beta_{0}$ and a nonzero $\beta_{1}$. Similarly, bad shocks can persist: a bad agricultural harvest in one year could lower the resources available to invest in the next years crop, lowering productivity in that year as well. In this setting, $\beta_{0}$ and $\beta_{1}$ would have the same sign.

If any of these dynamics are at play, then estimating (4) and summing contemporaneous and lagged effects will likely provide a more complete picture of the climate/conflict relationship than estimating (3) alone. Therefore, when presenting our second set of results using the standardized statistical model, we compute the cumulative effect of each climate variable by summing the effect of current and lagged climate conditions. We focus on this cumulative effect because our primary interest is whether climatic effects cause a net change in conflict rates over time, but inspection of individual lags also allows us to study whether climate events merely displace conflict into the future or whether climate events have delayed or persistent effects.

\subsubsection{Nonlinear responses}

Some studies assume a linear relationship between climatic factors and conflict risk, while others assume a nonlinear relationship. Taken as a whole, the evidence suggests that over a sufficiently large range of temperatures and rainfall levels, both temperature and precipitation are likely to have a nonlinear relationship with conflict. However, this curvature is not apparent in every study, probably because the range of temperatures or rainfall levels observed within a given kind enough to perform the re-analysis for us and share the results. 
sample is limited. Thus, most studies report only linear relationships that should be interpreted as local linearizations of a possibly curved global response function.

Some historical studies that examine temperate locations during cold epochs find that abrupt cooling from an already cold baseline temperature may lead to conflict. Yet, as we detail below, modern studies occurring during the current relatively warm epoch (1950-present) overwhelming obtain the result that warmer temperatures lead to more conflict. Taken together, this collection of locally linear relationships suggests a global U-shaped relationship between temperature and conflict-with most modern societies now on the warm, upward-sloping portion of the response curve.

In studies of rainfall effects, not all studies use the same parametrization of rainfall as an explanatory variable, making the determination between linear and non-linear responses more difficult. In a few cases where a wide range of rainfall levels are observed, such as the study by Hidalgo et al. (2010) examining the effect of rainfall on land invasions in Brazil, there is a clear nonlinear effect of rainfall on conflict. In an effort to make findings from these particular studies comparable to studies with linearized effects (the majority of studies), we follow the approach of Hidalgo et al. (2010) and use the absolute value of rainfall deviations from the mean as the independent variable, effectively linearizing the response function to rainfall on both sides of a U-shaped relationship.

\subsection{3 "Bad" control}

Some studies expand Equation 3 and Equation 4 to explicitly "control" for potential confounding factors, such as average national income. For example, Buhaug (2010a) altered the analysis of a temperature-war association studied in Burke et al. (2009) to include indices for political exclusion and average income. While well intentioned, this approach may introduce bias in the coefficients describing the effect of climate on conflict because these controls are endogenously determined and may themselves be affected by climate variation. This can cause the "signal" in the climate variable of interest to be inappropriately absorbed by the "control" variable and/or the estimate to be biased because societies differ in unobserved ways that become artificially correlated with climate when the "control" variable is included. This approach is commonly termed "bad control" (Angrist and Pischke (2008)), and is a particular difficulty in this setting because climatic variables may affect so many of the socioeconomic factors commonly included as control variables - things like crop production, infant mortality, population (via migration or mortality), and even political regime type. To the extent that these outcome variables are used as covariates, studies might draw mistaken conclusions about the relationship between climate and conflict. A detailed discussion of this issue specific to the climate-conflict context is in Hsiang, Burke, and Miguel (2013a). In what follows, we modify estimates that rely on this method by excluding "bad controls" in our re-analysis.

\subsubsection{Reduced form estimates vs. instrumental variables approaches}

We focus on the reduced form relationship between climatic variables and conflict variables. Many studies follow the influential early analysis by Miguel, Satyanath, and Sergenti (2004) 
where rainfall was used as an instrumental variable for economic growth when examining the effect of growth on civil conflict. However, with an increasing number of studies showing that climatic events can affect a variety of socio-economic outcomes (see Dell, Jones, and Olken (2013) for a review), the key identifying assumption in the instrumental variables approach - in this case that climate only affects conflict through a particular intermediary variable becomes increasingly hard to justify. Climatic events affect many factors that may in turn affect conflict, such as agricultural income (Schlenker and Lobell (2010)), human health (Burke, Gong, and Jones (2014)), and residential mobility (Bohra-Mishra, Oppenheimer, and Hsiang (2014)), among many others. Given these difficulties, we instead focus in this review on the total effect of climatic events on conflict as described by the reduced form. We interpret the reduced form as the net effect of climate on conflict operating through numerous potential channels. Formally, we conceptualize this total effect as

$$
\frac{\mathrm{d} \text { conflict_variable }}{\mathrm{d} \text { climate_variable }}=\sum_{i} \frac{\partial \text { conflict_variable }}{\partial \text { pathway }_{i}} \cdot \frac{\partial \text { pathway }_{i}}{\partial \text { climate_variable }}
$$

where pathway $_{i}$ is some variable characterizing an intermediary mechanism, such as income or human aggression. We focus on this total effect as a natural starting point because it is a quantity that can be reliably measured, but we will turn to a discussion of potential mechanisms and the extent of evidence supporting specific channels in a later section. In our view, identifying these channels is a central task for future research.

\subsection{What we know so far}

Econometric studies have examined different conflict outcomes that span the full spectrum of scales of human organization. For example, Figure 1 displays results from four different studies that analyze nested spatial scales: Tanzanian villages (Miguel (2005)), $1^{\circ}$ grid-squares of East Africa (O'Loughlin et al. (2012)), countries in Sub-Saharan (Burke et al. (2009)), and the global tropics (Hsiang, Meng, and Cane (2011)). The top panels display the nested structure of the spatial units analyzed, while the corresponding bottom panels display the conditional probability of conflict at that unit of analysis. These "watercolor regression" plots use the darkness of color saturation to display the probability that the conditional expectation function passes through a given point, out to the $95 \%$ confidence interval, using a bootstrapped distribution of estimates (Hsiang (2012)).

At all scales, while there is some commonality in how conflict rates respond to climatic events, we observe enough systematic differences that we categorize conflicts into two classes that we subsequently evaluate separately: (1) interpersonal conflict, and (2) intergroup conflict. Interpersonal conflicts are conflicts between individuals, which includes various acts commonly described as crime, such as assault, rape and robbery, as well other types of conflict that may not necessarily be criminal, such as violence in sporting events, road rage and violent acts by police. Intergroup conflicts are conflicts between collections of individuals, such as organized political violence, civil conflicts, wars, riots and land invasions.

In earlier work (Hsiang, Burke, and Miguel (2013a)), we described a third class of conflict 
that we termed "institutional breakdown and population collapse." These events, such as the disintegration of Chinese dynasties and the collapse of Icelandic populations, are certainly of interest to economists; however, most of the quantitative analysis we draw on to understand these events is undertaken by archeologists, paleoclimatologists and historians who do not analyze these data in the econometric framework described above. For this reason, we have omitted these studies from this review, although we do think there are important economic insights to be gleaned from these studies and we encourage economists to analyze these events in future research, especially as new panel data become available.

In new work, Gonzalez et al. (2014) describe a fourth class of violent conflict that may also respond to climatic events: intrapersonal conflict. Using the econometric framework above, Gonzalez et al. (2014) demonstrate that suicides in Mexico are positively correlated with local temperature. However, because this is the only study of the subject to employ this econometric approach (to our knowledge), we do not review this fourth class here either, although we do discuss this study in the context of other classes of conflicts that it analyzes (including both interpersonal and intergroup violence). We hope that future work will establish whether a effect of climate on suicide and other forms of intrapersonal violence is present in other contexts.

\subsubsection{Interpersonal conflict}

Experimental studies in psychology have long observed that individuals are more likely to behave violently towards one another if ambient temperatures are higher (Rohles (1967), Kenrick and Macfarlane (1986), Vrij, der Steen, and Koppelaar (1994)). This behavior might contribute to results of natural experiments that use versions of Equation 3, where it is generally found that crimes between individuals - particularly violent crimes such as assault, murder, rape, and domestic violence - tend to increase at higher temperatures in Australia (Auliciems and DiBartolo (1995)), India (Blakeslee and Fishman (2014), Iyer and Topalova (2014)), Mexico (Gonzalez et al. (2014)), the Philippines (Wetherley (2014)), Tanzania (Burke, Hsiang, and Miguel (2014)), and the United States (Anderson et al. (2000); Anderson, Bushman, and Groom (1997); Bushman, Wang, and Anderson (2005); Card and Dahl (2011); Cohn and Rotton (1997); Jacob, Lefgren, and Moretti (2007); Mares (2013); Ranson (2014); Rotton and Cohn (2000)). Table 1 presents a detailed listing of these studies.

Ranson (2014) is among the most detailed of these analyses. Conducted using U.S. data, Ranson separately documents a non-linear effect of temperature on property crime, with property crimes increasing up until about $70^{\circ} \mathrm{F}$, and documents a remarkably linear effect of temperature on violent crimes, such as murder. Remarkably, the effect of temperature on crime in the United States has remained virtually unchanged since 1960 and is relatively uniform across the country. Jacob, Lefgren, and Moretti (2007) document that there is some temporal displacement of crimes in the United States, with high temperatures elevating crimes in the contemporaneous week but then lowering crimes in later weeks, although the combined effect is significantly positive. Larrick et al. (2011) document that the probability of violent retaliation in sporting events increases on hot days and Vrij, der Steen, and Koppelaar (1994) find that police officers are

more likely to draw and fire their weapon at an assailant during a training simulation conducted 
at hot temperature.

In low-income settings, extreme rainfall events that adversely affect agricultural income (too much or too little rain) are also associated with higher rates of personal violence and property crime (Blakeslee and Fishman (2014); Iyer and Topalova (2014); Mehlum, Miguel, and Torvik (2006); Miguel (2005); Sekhri and Storeygard (2012)). Analysis of U.S. data suggests that rainfall does not have substantial effects on crime in this primarily non-agricultural economic setting (Ranson (2014)).

Wetherley (2014) is the only study, to our knowledge, to estimate the effect of climatic disasters on crime. Wetherley (2014) finds that a year after Filipino communities are exposed to strong typhoon winds, property crime rises. This lagged structure mirrors the lagged effect of typhoons on household income and consumption in the Philippines (Anttila-Hughes and Hsiang (2012)).

\subsubsection{Intergroup conflict}

Historical analyses of temperate or cold locations have found that anomalously cold events during cold epochs are associated with episodes of political instability in dynastic China and feudal Europe (Tol and Wagner (2010); Zhang et al. (2007, 2006, 2011)) as well as inter-ethnic violence in Europe (Anderson, Johnson, and Koyama (2013)). Drying events - periods of low rainfall - have also triggered political instability in historical Egypt (Chaney (2013)), Europe (Lee et al. (2013)), and China (Jia (2013); Kung and Ma (2012)), and have fueled transboundary invasions of nomadic populations in historical China (Bai and Kung (2010)).

In analyses of the modern period (1950-present), a relatively warm epoch by historical standards, high temperatures elevate the risk of many forms of intergroup conflict, both political violence and other forms of collective violence (Burke et al. (2009); Caruso, Petrarca, and Ricciuti (2014); Dell, Jones, and Olken (2012); Gonzalez et al. (2014); Hsiang, Meng, and Cane (2011); Hsiang, Burke, and Miguel (2013b); Maystadt, Calderone, and You (2014); Maystadt and Ecker (2014); O'Loughlin et al. (2012)). In all cases, these effects are observed primarily in low and middle income settings where populations are exposed to warm or hot temperatures on average. This linear effect is conspicuously similar in sign and structure to the response of interpersonal conflict to temperature, and it can be observed at scales ranging from gang violence (Gonzalez et al. (2014)) to the risk of civil conflicts throughout the entire global tropics (Hsiang, Meng, and Cane (2011)).

Also in the modern period, studies find that low or declining rainfall increases the risk of communal conflict, such as Hindu-Muslim riots in India (Bohlken and Sergenti (2010); Sarsons (2011)) or land invasions in Brazil (Hidalgo et al. (2010)), as well as organized political conflict (Cervellati, Sunde, and Valmori (2011); Couttenier and Soubeyran (2013); Fetzer (2014); Fjelde and von Uexkull (2012); Harari and La Ferrara (2013); Hendrix and Salehyan (2012); Hsiang, Meng, and Cane (2011); Levy et al. (2005); Miguel, Satyanath, and Sergenti (2004); O'Loughlin et al. (2012)), leadership changes (Burke (2012); Dell, Jones, and Olken (2012)), and coups (Kim (2014)). In some settings where a large range of rainfall levels are observed, it is also found that exceptionally high levels of rainfall increase rates of communal conflict relative to average rainfall 
conditions (Hendrix and Salehyan (2012); Hidalgo et al. (2010); Ralston (2013)), suggesting a global response function that is probably U-shaped. Again, these effects are observable primarily in low and middle income settings where the economic impacts of climatic variation are likely to be substantial due to their importance to local agricultural production. Table 1 contains a detailed listing of these studies.

\subsection{Comparing and combining results from modern samples}

Broadly speaking, the econometric literature surveyed above suggests that different classes of conflict, in different contexts and at different scales of analysis, share the general feature that their likelihood of occurring is influenced by climatic events. This qualitative statement, while conceptually intriguing, is alone unsatisfying because there remain many differences between studies, making it difficult to determine what, if anything, can be said about a more general quantitative relationship between climate and conflict. Furthermore, there is substantially more uncertainty in the results of some studies due to the nature of their data, making it imperative that point estimates from individual studies are not over-interpreted and that statistical uncertainty is accounted for when assessing the extent of agreement between studies (Hsiang et al. (2013c); Hsiang and Meng (2014)). Finally, the strength of statistical conclusions that we can draw from the literature as a whole may be substantially stronger than the strength of conclusions from individual studies because the larger body of literature draws on far more data than individual studies - so long as there is a reasonable way to combine these varied sources of data. For these three reasons, we standardize effect sizes (and in some cases statistical models) as described below so that results from different studies may be compared to one another more systematically. We then implement a meta-analysis to synthesize existing results into more general findings. Importantly, the meta-analytic technique we employ does not assume that all effect sizes are identical, as they certainly are not, but instead tries to identify whether there is a common component in the results while simultaneously characterizing the degree of heterogeneity in treatment effects across studies.

\subsubsection{Standardizing and comparing effect sizes}

To compare quantitative results across studies of modern data, we computed standardized effect sizes for those studies where it was possible to do so. Standardization is essential for an applesto-apples comparison of results across studies for two reasons.

First, most studies report changes in the probability of conflict, but different types of conflict (within both classes of conflict, interpersonal and intergroup) exhibit different baseline frequencies. For example, a 0.1 change in probability for a conflict that occurs with a baseline probability of 0.3 has a very different interpretation (a $33 \%$ increase in risk) than the same change in probability for a type of conflict that occurs with a baseline probability of 0.01 (a $1,000 \%$ increase in risk). Hsiang and Meng (2014) point out that in prior research on Africa, comparing probability changes for civil conflict incidence and civil war outbreak is an applesto-oranges comparison since they have baseline probabilities of 0.25 and 0.012 , respectively. To adjust for baseline probabilities, we convert marginal changes in probabilities to marginal 
changes in relative risk, normalizing probability by the average risk of conflict in the observed sample.

Second, most studies report changes in climate variables in physical units, such as degrees of temperature or millimeters of rainfall, but different locations around the world exhibit different within-location baseline variances in these measures, which is further exacerbated by differences in the areal extent that is averaged over to compute exposure levels. For example, a $1^{\circ} \mathrm{C}$ temperature change is a relatively small change for average weekly temperature in a U.S. county, however it is an enormous change for annual average temperature in an African country. To adjust for these large differences in baseline climate variance, we convert all physical measures of climate into standardized measures based on the within-location standard deviation in climate.

Thus, for a coefficient reporting the marginal change in probability of conflict caused by a 1 physical unit change in climate, we convert to standardized units

$$
\beta_{\text {standardized }}=\beta_{\text {reported }} \cdot \frac{\sigma(\text { climate })}{\operatorname{avg}(\operatorname{Pr}(\text { conflict }))}
$$

which is the change in the relative risk of conflict for each standard deviation change in climate variables, and where $\sigma$ (climate) is the within-location standard deviation in the climate variable. We focus on computing this effect for studies using modern data (1950-present).

We plot these standardized $\beta$ 's for each author's preferred model and variables in Figures 2-3, displaying interpersonal and intergroup conflict respectively. Temperature effects are shown as red, rainfall effects as blue (and the smaller number of studies focusing on El Niño, drought and disasters are in maroon, orange and grey, respectively). The utility in distinguishing between these two classes of conflict is immediately apparent, as the overall magnitude and precision of estimates for these two classes appear quite different. The reported effect of climate on interpersonal conflict (Figure 2) has generally smaller effects, with point estimates in the single digits, and most effects are precisely estimated and statistically significant individually. The reported effect of climate on intergroup conflict (Figure 3) tends to be larger, with standardized values spanning $0-40 \% / \sigma$, and with each individual estimate exhibiting larger confidence intervals. The greater precision of interpersonal estimates is in part due to the very large number of interpersonal conflicts that are observed in data (i.e., there are many more murders than civil wars), and the large and high resolution data sets (in both spatial and temporal dimensions) used to study these effects, such as the FBI Uniform Crime Reports (Jacob, Lefgren, and Moretti (2007); Ranson (2014)). Overall, we observe visually that once effect sizes are standardized and conflicts are separated by class, there appears to be considerable consistency across studies on the reported relative influence of climate on conflict.

One concern with these results, raised in Hsiang, Burke, and Miguel (2013a), is that there may be some selectivity by authors in which results they present and how their results are framed in their analysis. For example, not all studies examine both the effects of temperature and rainfall (or they use some transformation of these variables to describe drought or water availability) and not all studies account for the potential effect of climate variables in prior periods. These modeling decisions are sometimes based on data availability and in many cases 
represented best practices at the time the study was conducted. However, there is growing awareness that climate variables such as temperature and rainfall may be highly correlated with one another contemporaneously and autocorrelated over time (Auffhammer et al. (2013)), indicating that estimates constructed without multiple climate variables and lags may be biased due to omitted variables. Furthermore, some authors may focus (consciously or not) on the effect of climate variables that are most statistically significant, so summarizing authors' preferred results may introduce some selection bias into parameter estimates.

To address this issue, we compute standardized estimates for the cumulative (contemporaneous + lagged) temperature and rainfall effects for all studies where it was possible to do so, and report both the temperature and rainfall coefficients instead of only focusing on the authors' preferred choice. This approach substantially reduces the number of studies we can include in the analysis - we do not have access to the data needed to compute cumulative effects and their standard errors for many studies shown in Figures 2-3 - but it also substantially reduces the "degrees of freedom" authors have over which particular results are displayed.

Results from this more refined analysis are shown in Figures 4-5. In the case of interpersonal conflict (Figure 4), results suggest that the effects of cumulative temperature and rainfall are highly consistent, with temperature having effects clustered tightly around the $2 \% / \sigma$ median estimate and rainfall having close to a zero effect. Results for intergroup conflict (Figure 5) become similarly clarified with this refinement, with temperature having a strong cumulative effect $($ median $=18 \% / \sigma)$ and slightly smaller estimates appearing for rainfall $($ median $=11 \% / \sigma)$, although as before these estimates are less precise than for interpersonal conflict.

\subsubsection{Identifying mean effects and heterogeneity through meta-analysis}

Ideally we would like to systematically characterize the extent to which there is a link between climate and conflict that is general across societies. However, in light of the discussion above, it is clear that different types of conflict in distinct contexts respond to climate events heterogeneously, even within a class of conflict. Thus, any attempt at summarizing results from the literature must take into account these differences, even if the goal is to identify common features of the response. To achieve this, we adopt the method proposed in Gelman et al. (2004) and employ a hierarchical Bayesian approach to meta-analysis of this literature. This approach recognizes that the true effects underlying different parameter estimates may indeed be distinct from one another, and is designed to characterize the extent of this cross-study heterogeneity as well as any common component across studies. The magnitude and precision of this common component represents the generalizable conclusions we might draw from this growing literature.

In each study $j$, we compute the standardized effect $\hat{\beta}_{j}$ and standard error for that estimate $\hat{\sigma}_{j}$, using the regression models described above. Following Hsiang, Burke, and Miguel (2013a) we assume that there is some common component to these results $\mu$ but that there might also be heterogeneity in how different populations are affected by the climate. That is, we allow for the fact that the cross-study differences that we observe might not be driven only by sampling variability, i.e. that even if each study were executed with infinite data we would not expect them to obtain the exact same parameter estimate. This situation is well suited for a random 
effects framework where we assume that the "true" $\beta_{j}$ that generates the data in each study can be thought of as being drawn from a distribution of all possible samples and studies where:

$$
\beta_{j} \sim N\left(\mu, \tau^{2}\right)
$$

and where $\mu$ and $\tau$ are unobserved "hyperparameters" that determine the central tendency and dispersion of findings in the literature. $\mu$ is the generalizable component describing the mean response to changes in climate. $\tau$ describes the extent of heterogeneity across contexts in these responses. If $\tau$ is much larger than $\mu$, then differences between results are much larger than their commonalities. We point out here that if $\mu$ is large, this may be of theoretical or policy interest regardless of whether $\tau$ is large or not, and if $\tau$ is large it suggests there are substantial differences between studies that may be worth modeling explicitly. For instance, rainfall may have distinct effects on conflict across settings with differential economic dependence on agriculture. Our objective is to estimate both $\mu$ and $\tau$. Specifically, we estimate these values separately for the effects of both current and lagged temperature and rainfall, separately for both interpersonal and intergroup conflict.

Under a uniform prior, the conditional posterior for $\mu$ is

$$
\mu \mid \tau, y \sim N\left(\hat{\mu}, V_{\mu}\right)
$$

where

$$
\hat{\mu}=\frac{\sum_{j} \frac{1}{\hat{\sigma}_{j}^{2}+\tau^{2}} \hat{\beta}_{j}}{\sum_{j} \frac{1}{\hat{\sigma}_{j}^{2}+\tau^{2}}}, \quad V_{\mu}^{-1}=\sum_{j} \frac{1}{\hat{\sigma}_{j}^{2}+\tau^{2}}
$$

where $\tau$ is computed to have larger values if the between-study differences in $\hat{\beta}_{j}$ are large relative to the within-study standard error estimates $\hat{\sigma}_{j}$ (the standard errors normally reported for individual regression results). When differences in estimates across studies are large relative to uncertainty in parameter estimates within studies, then studies are treated nearly uniformly when estimating an average effect. Meanwhile, if $\tau$ is close to zero then it is more likely that the true $\beta_{j}$ are drawn from a narrow distribution and sampling variability drives most of the variation in the estimates $\hat{\beta}_{j}$. In this case, the weight on each study approaches its precision $\frac{1}{\hat{\sigma}_{j}^{2}}$ and estimates with large uncertainty are down-weighted. In the limit that $\tau \rightarrow 0$, this estimate approaches the optimal composite parameter estimate for the case where each study examines different subsamples of the same population, which is only exactly true when $\tau=0$.

Intuitively, if estimated treatment effects in all studies are near one another and have relatively wide and overlapping confidence intervals, then most variation is likely due to sampling variation and the value of $\tau$ (the degree of treatment effect heterogeneity across studies) is likely to be close to zero. Alternatively, if there is extensive variation in the estimated average treatment effects but each effect is estimated quite precisely, then $\tau$ will be relatively large and there is likely to be considerable heterogeneity in treatment effects across studies, since sampling variation alone is unlikely to be able to explain this pattern of results. Casual observation of Figures 2-5 suggests a climate-conflict literature somewhere in between: there is substantial overlap in confidence intervals, but also substantial variation in the estimated effects with some 
confidence intervals that do not overlap.

Using a uniform prior, we apply Bayes' Rule to update our estimates of $\mu, \tau$ and the $\beta_{i}$ 's for estimates of interpersonal violence and intergroup conflict separately. We then use 10,000 simulations to characterize the posterior distributions of each of these variables ${ }^{3}$.

Meta-analysis of authors' preferred results We first present the posterior mean and confidence interval for the common component $\mu$ using each author's preferred climate measure and model. These values are shown for interpersonal conflict and intergroup conflict as the white circle with whiskers in the grey panels of Figures 2-3, respectively. The probability distribution in these panels displays the posterior distribution for $\beta_{i}$ 's, i.e., the distribution of effects we would expect to obtain if we were to implement a new study. Pooling authors' preferred results, we estimate that for each $1 \sigma$ change in climate towards hotter, drier, or more extreme rainfall conditions, interpersonal conflict rises $2 \%$ and intergroup conflict rises $11 \%$. Both of these estimates are highly statistically significant (P-value $<0.01$; see Table 2$)$.

Cumulative effects for all climate variables We then consider our re-analyzed results that account for both potential lagged effects of climate on conflicts, including possible forward displacement in time. The white marker with whiskers and the black probability distribution in Figures 4-5 display these results for interpersonal and intergroup conflict, respectively, pooling all climate variables regardless of whether an author emphasized a particular climate variable in their analysis. Computing cumulative effects, we find that on average interpersonal conflict rises $1.2 \%$ and intergroup conflict increases $4.5 \%$ for each $1 \sigma$ change in climate towards more adverse conditions (see "All Estimates" panel in Figures 4-5), with both effects being highly significant $(\mathrm{P}$-value $<0.01)$. This suggests that on average, climatic shifts have a net effect on conflict rates and do not only displace conflicts forwards or backwards in time.

Results broken down by climate variable Because our re-analysis treats climate variables identically, we look separately at the cumulative effects of temperature and precipitation. (For this exercise, we classify variables that are not simply direct temperature or rainfall exposure as whichever atmospheric variable is actually used to define exposure - i.e., exposure to drought in Brückner and Ciccone (2011) is coded as rainfall and exposure to El Niño-Southern Oscillation (ENSO) in Hsiang, Meng, and Cane (2011) is coded as temperature.) The rightmost gray panels in Figures 4-5 display results for temperature and rainfall separately for both classes of conflict, with results also presented in Table 2. For interpersonal conflict, temperature and rainfall have clearly distinguishable cumulative effects, with the $2.1 \% / \sigma$ effect of temperature roughly 7 times larger than the $0.3 \% / \sigma$ effect of rainfall, although this small effect of rainfall is still statistically different from zero (P-value $<0.05)$.

For intergroup conflict, higher temperature has a much larger average effect and also greater dispersion across study estimates, with each $1 \sigma$ increase in temperature increasing intergroup conflict $11.3 \%$ on average $(\mathrm{P}$-value $<0.01)$. Notably, the posterior distribution of $\beta_{i}$ is negative

\footnotetext{
${ }^{3}$ Details of our approach to hierarchical Bayesian meta-analysis closely follow Gelman et al. (2004), to which we refer readers for further technical details.
} 
for one-tenth of values, suggesting that cross-study heterogeneity is large enough to generate negative estimates in individual studies even when the common component $\mu$ is positive and well-separated from zero. The common component of rainfall effects on intergroup conflict are also positive but smaller, at 3.5\%/ $\sigma$ and are also statistically significant $(\mathrm{P}$-value $<0.05)$. The greater cross-study dispersion in temperature effects relative to rainfall effects are described by the hyperparameter $\tau$, which is $14.4 \% / \sigma$ for the cumulative temperature effect and $3.1 \% / \sigma$ for rainfall (Table 2). Uncertainty over $\tau$ is also larger for temperature, suggesting that the extent of cross study differences are perhaps more difficult to characterize. This appears largely due to the combination of dispersed point estimates, each of which has relatively large uncertainty (Figure 5), making it challenging to determine if cross-study differences represent meaningful differences in context or if they are mostly due to sampling variability.

Thus, while there is strong evidence of important differences between studies, there is simultaneously strong evidence of some underlying commonality between studies, namely a link between more extreme climate and conflict. There remains considerable heterogeneity in the response to climate across studies that should be recognized, and understanding the sources of this variation is an important area for future inquiry.

Results broken down by timing of effects The above results suggest that temperature and rainfall have a discernible cumulative effect on conflict. However, it is also useful to decompose the common component of cumulative effects into a common component for each time period (current and lagged) because understanding the timing of these average effects provides insight into mechanisms that might be driving the cumulative result. Thus, we compute a separate value for $\mu$ for both classes of conflict, for both climate variables, and for both lags - effectively characterizing multi-dimensional impulse-response functions that are the generalizable component for the effect of climate on conflict ${ }^{4}$. These results are shown in Figure 6 and presented in Table 2.

We find substantial and statistically significant effects of contemporaneous temperature on both interpersonal and intergroup conflict, with lags that are smaller and not significantly different than zero. The $11.3 \% / \sigma$ effect of contemporaneous temperature on intergroup conflict is roughly four times larger than the $2.8 \%$ / $\sigma$ lagged temperature effect; however, both are positive, suggesting that on average, the temperature effect of climate on conflict is not due to displacement alone. Similarly, the $2.4 \% / \sigma$ effect of contemporaneous temperature on interpersonal conflict is much larger than the $-0.23 \% / \sigma$ lagged effect, which suggests that roughly one-tenth of the observed effect is attributable to temporal displacement.

The effect of rainfall on intergroup conflict is smaller than the effect of temperature but it remains statistically significant, although interestingly there is roughly the same sized effect for both contemporaneous and lagged rainfall, which may not be surprising in agrarian settings where lagged rainfall is a key input into current harvests and thus local economic conditions. The effects of both current and lagged rainfall on interpersonal conflict are small, although

\footnotetext{
${ }^{4}$ Here we can add back in a few studies that were omitted in the cumulative effects calculations - studies that report both contemporaneous and lagged effects but for which we do not have access to the data to calculate the cumulative effect and its standard error. The number of studies contributing to each estimate is shown in the last column in Table 2.
} 
the contemporaneous $0.6 \% / \sigma$ effect of rainfall is highly statistically significant and the lagged effect of $-0.2 \% / \sigma$ suggests that roughly one-third of this effect is attributable to temporal displacement.

\subsubsection{Publication bias}

Evidence increasingly suggests that many empirical social science literatures exhibit some form of publication bias (Brodeur et al. (2013); Gerber and Malhotra (2008a,b)), with a common form of bias arising from the research community's reluctance to investigate or publish null results. This is generally thought to manifest in two ways in a literature. First, authors may never release their data or findings if they obtain a null result early on in their investigation. This is known as the "file drawer" problem because these researchers return their findings to a proverbial file drawer where no other member of the research community observes them (Rosenthal (1979)). This source of publication bias is difficult to combat because it is generally difficult or impossible to observe what researchers investigate but do not report (see Franco, Malhotra, and Simonovits (2014) for a discussion of how this is sometimes possible in practice). However, we think this issue is generally less likely to be problematic in the climate-conflict literature because many papers have been published reporting associations that are not statistically significant (Buhaug (2010a); Couttenier and Soubeyran (2013); Theisen, Holtermann, and Buhaug (2011)). In particular, these analyses are often framed as interesting precisely because they present an alternative finding on a controversial topic and can accrue substantial scholarly and media attention as a result. Thus, we believe that the high profile and large number of previous positive results in this literature create strong incentives to not withhold null results or negative results.

A second potential source of publication bias is that authors may conduct multiple statistical tests in their analysis, for example varying climate variables, conflict variables, or subsamples, and report only their strongest findings. These findings may not be representative of the data, and furthermore they may exhibit spurious correlations because statistical uncertainty is generally not corrected for the multiple testing. Implicit norms in the research community sometimes can address this issue, in the form of journal referees often requiring that authors demonstrate a single result multiple ways, for example by using different sources of variation, placebo tests, and cross-partial effects (eg. Burke et al. (2009); Hsiang, Meng, and Cane (2011); Dell, Jones, and Olken (2012)). The logic is that a single test may prove spuriously significant if repeated enough times on different variables, but it is dramatically less likely for multiple, orthogonal tests of a single result to be spuriously significant. Nonetheless, many findings are published with a single hypothesis test, exposing this literature to this second potential source of bias. To the extent that this form of bias is driven by authors selecting a preferred specification, temporal lag, or climate variable, our re-analysis of results should in principle correct for this bias-implying that Figures 4-6 are likely to be less biased than the authors' preferred specifications.

Nevertheless, we look for evidence of publication bias across our full sample of studies (i.e. whether or not we have their replication data) by examining whether the statistical strength of individual studies reflects their sample size. Following Card and Krueger (1995) and Disdier and Head (2008), standard sampling theory suggests that the $t$-stat on a coefficient estimate should 
be proportional to the degrees of freedom in the study. In particular, with the null hypothesis $H_{0}=0$, vector of independent variable observations $X$, vector of residuals $\varepsilon$, degrees of freedom $n-k$, and again indexing studies by $j$ :

$$
t\left(\hat{\beta}_{j}\right)=\frac{\hat{\beta}_{j}}{\hat{\sigma}_{j}}=\frac{\hat{\beta}_{j}}{\left(\frac{\sqrt{\varepsilon_{j}^{\prime} \varepsilon_{j}}}{\sqrt{n_{j}-k_{j}} \sqrt{X_{j}^{\prime} X_{j}}}\right)}=\sqrt{n_{j}-k_{j}} \times\left(\frac{\hat{\beta}_{j} \sqrt{X_{j}^{\prime} X_{j}}}{\sqrt{\varepsilon_{j}^{\prime} \varepsilon_{j}}}\right)
$$

Taking logs, we see that there should be unit elasticity between the log of the t-stat and the $\log$ of the square root of the degrees of freedom. We use this insight to look for evidence of publication bias in the literature we analyze. If there is a true relationship between climate and human conflict, then we expect the statistical power of studies to increase with their sample size (and thus with their degrees of freedom). However, if there is no true relationship, and instead authors are just searching through data until they find data that allows them to reject a null hypothesis at $95 \%$ confidence, then large sample sizes should provide no benefit in terms of statistical power. Thus, if publication bias is a major problem in this literature, we predict that $\log \left(t\left(\hat{\beta}_{j}\right)\right)$ should not increase with $\log (\sqrt{n-k})$. For example, in Card and Krueger (1995), the authors found a negative relationship between t-stats and degrees of freedom, which they interpreted as strong evidence of publication bias.

Figure 7 shows the plotted relationship between the log of the t-statistic and the log of the square root of the degrees of freedom, for the 40 estimates for which we are able to calculate standardized effects (we use author-reported statistics here because those are the values that authors, editors and reviewers would consider at the time of release/publication). The unit elasticity is given by the 45-degree line, and OLS estimates of the relationship for the full sample and for the temperature- and precipitation-focused studies are given by the dashed lines. We strongly reject a slope of zero for both the full sample and the temperature subsample ( $p<0.01$ and $p<0.05$, respectively), and marginally reject a zero slope for the precipitation estimates $(p<0.10)$. And although we can also reject a 1-to-1 relationship for each sample, studies with larger sample sizes on average do have larger t-statistics in the climate and conflict literature we survey, suggesting that authors with large samples are not simply searching through specifications or data mining to find significant effects at exactly $95 \%$ confidence. We note that for both samples, the upward relationship stands in sharp contrast to the results in Card and Krueger (1995), with the negative slope they estimate. Our estimates are more similar to that of Disdier and Head (2008), who interpret their results as ruling out any large role for publication bias in the trade literature that they survey.

\section{Understanding the mechanism}

Reduced form evidence in the literature indicates a causal effect of climatic events on multiple forms of conflict (Figure 6). As described by Equation 5, this reduced form effect is the sum effect of all potential pathways. Thus, taken alone, these reduced form effects say little about what mechanisms play a role in generating this response. Understanding what mechanisms drive 
observed patterns is not essential for all applications of these results: for example, under some assumption the social impact of climate change can be estimated using just these reduced form results (as discussed below), and law enforcement or humanitarian organizations can use climate forecasts for planning purposes without understanding all the underlying mechanisms. However, many scientific questions and policy interventions do require an understanding of the mechanisms

linking conflict to climate. For instance, a more detailed understanding of the processes involved is necessary for implementing policies to reduce conflict risk in hot periods. Here we present a simple framework to describe several mechanisms that researchers have highlighted, describe the evidence to date on hypothesized pathways, and conclude that studying mechanisms should be a central task for future research.

\subsection{Framework}

We employ the theoretical model developed in Chassang and Padro-i-Miquel (2009) to illustrate potential channels. In this model, two agents decide whether to engage in costly conflict and redistribution when bargaining fails. We opt not to present a full solution to the model here but instead focus on using the framework to provide an illustration of key ideas (we refer readers to the original paper for solution details). We follow Gonzalez et al. (2014) by enriching the basic model with additional mechanisms that have been proposed but were not in the original analysis.

Consider two agents that cannot commit to not attacking one another in an infinite number of periods, indexed by $t$. Each agent has assets with productivity $\theta_{t}$ that produces $\theta_{t} l$ output when combined with $l$ units of labor (Chassang and Padro-i-Miquel (2009) set $l=1$ ). We enrich the model to account for a population $n_{t}$ (not all of which must be laborers) that consume this output for a per capita per period consumption of $\frac{\theta_{t} l}{n_{t}}$ under non-conflict conditions. If one of the agents attacks the other first, then it gains a first-strike advantage and captures all of the opponent's output and assets with probability $P_{t}>0.5$. Such an attack costs both the aggressor and defender a fraction $c>0$ of output. If both agents choose to attack simultaneously, they each win with probability 0.5. Following Gonzalez et al. (2014), an attacker experiences a nonrival psychological consumption value of violence $\gamma_{t}$; if the attacker dislikes being violent, then $\gamma_{t}<0$ and if the attacker derives positive utility from violence $\gamma_{t}>0$.

Following the original formulation, if an agent loses the conflict, then she is removed from the game. If there is no attack in the current period, then each agent expects a peaceful continuation value $V^{P}$, which is the discounted per capita utility of expected future consumption from the agent's initial assets and which captures expectations about future values of all parameters. Similarly, if an attacker wins, then they have a continuation value of victory $V^{V}$ which is the per capita expected utility from consumption of both their initial assets and the assets that they capture from their opponent. $\delta$ is the per period discount rate.

Chassang and Padro-i-Miquel (2009) show that the condition for no-conflict is (modified for 
the new terms $n_{t}$ and $\left.\gamma_{t}\right)$ :

$$
\underbrace{\frac{\theta_{t} l}{n_{t}}+\delta V^{P}}_{\text {value of peace }}>\underbrace{P_{t}\left(2 \frac{\theta_{t} l}{n_{t}}(1-c)+\delta V^{V}\right)+\gamma_{t}}_{\text {value of attacking }}
$$

In words, an agent finds it privately beneficial not to attack if the per capita value of consuming all output with initial assets plus discounted expected utility under peace $\delta V^{P}$ exceeds the expected utility of consumption from both the agent's original assets and captured assets, less expenditures on the conflict, plus the expected continuation value $P_{t} \delta V^{P}$ and the consumption value of violence $\gamma_{t}$, which is experienced with certainty.

Chassang and Padro-i-Miquel (2009) only apply this result to intergroup conflicts, particularly focusing on organized political violence. But interpreted heuristically, Equation 11 can be generalized to describe both interpersonal and intergroup conflicts. In interpersonal conflicts, $l=n_{t}=1$ and $V^{V}$ contains information on an agent's expectation that they will be apprehended and punished for the attack. In purely violent crimes that involve no intention to transfer wealth between individuals, such as some murders, assaults, and rapes, then we consider $\theta_{t}=0$ and $\gamma_{t}$ provides the primary motivation for the attacker.

Following Chassang and Padro-i-Miquel (2009), we can rearrange Equation 11 so that the condition for no conflict becomes

$$
\frac{\theta_{t} l}{n_{t}}\left(1-2 P_{t}(1-c)\right)-\gamma_{t}>\delta\left[P_{t} V^{V}-V^{P}\right]
$$

where the left side of the inequality is the marginal value of peace in the current period weighed against the discounted marginal expected utility from attacking on the right side. For expositional purposes, we assume that initially this inequality is satisfied and thus there is no conflict. From that baseline, we can then consider how marginal changes in parameter values driven by climate might cause this inequality to be violated, and we do this in the next subsection.

\subsection{Indirect evidence}

Among economists, the majority of attention has focused on the potential for climatic conditions to adversely affect economic productivity $\theta_{t}$ and associated living standards. In the framework above, a temporary reduction in productivity reduces the current opportunity cost of conflict more than it alters the value of victory because the productivity loss is temporary. Miguel, Satyanath, and Sergenti (2004) hypothesize that adverse rainfall conditions could increase the risk of African countries because these changes temporarily lowered agricultural productivity, and many studies since have argued or alluded to a similar mechanism (Brückner and Ciccone (2011); Burke et al. (2009); Burke (2012); Burke and Leigh (2010); Dell (2012); Jia (2013); Kim (2014); Maystadt and Ecker (2014); Miguel (2005)). It is now increasingly well documented that climatic events similar in structure to those that increase conflict risk (hot and dry, or very wet) also reduce productivity in agriculture (Hidalgo et al. (2010); Hsiang, Meng, and Cane (2011); Lobell, Schlenker, and Costa-Roberts (2011); Schlenker and Lobell (2010); Schlenker 
and Roberts (2009); Welch et al. (2010)) as well as nonagricultural incomes (Barrios, Bertinelli, and Strobl (2010); Dell, Jones, and Olken (2012); Graff Zivin and Neidell (2013); Hsiang (2010); Jones and Olken (2010)), making this a plausible assertion. Further, there is some evidence that positive income shocks reduce the likelihood of certain types of conflict (Berman, Shapiro, and Felter (2011); Dube and Vargas (2012); Iyengar, Monten, and Hanson (2011)), although there are also findings that suggest a limited or opposite effect of income on conflict risk (Arezki and Brueckner (2104); Berman, Felter, and Shapiro (2011); Crost, Felter, and Johnston (2014); Dube and Vargas (2012)). However, even if it were true that income affected conflict risk, and climate affects income, these two facts on their own are insufficient to prove that climate affect conflict mainly through income, following our discussion in Section 2 on the appropriate use of instrumental variables approaches.

An alternative approach to looking for an income channel is to demonstrate that the pattern in which climate affects income is similar to the pattern for how the climate affects conflict. For example, Hidalgo et al. (2010) match functional forms by demonstrating that the nonlinear inverted-U shaped relationship between agricultural income and rainfall in Brazilian municipalities is almost a mirror reflection of the U-shaped relationship between land-invasion risk and rainfall in the same municipalities. In a different example, Hsiang, Meng, and Cane (2011) match patterns of heterogenous responses to climate for both income and conflict, showing that both income and conflict are correlated with the timing of ENSO only in the tropics and not at higher latitudes. In other examples, studies match the timing of climatic events that affect conflict with the timing of climatic events that are thought to be economically important. For example, Fetzer (2014) and Blakeslee and Fishman (2014) both show that monsoon rainfall affects conflict in India more than non-monsoon rainfall, and Caruso, Petrarca, and Ricciuti (2014) find that high minimum nighttime temperatures that are known to adversely affect rice yields (e.g. Welch et al. (2010)) predict the risk of conflict in Indonesia. Taken together, these exercises provide suggestive evidence that an economic productivity channel is likely to play a meaningful role. However, they are not conclusive since many other economic and social factors may simultaneously be affected by climatic conditions and thus exhibit similar patterns (Dell, Jones, and Olken (2013)), and it could still be the case that climatic conditions affected productivity because they affect conflict.

Less focus has been paid to the potential role of population density changes, although some existing evidence suggests this pathway might play a role. In Equation 12, if climatic conditions cause the total population $n_{t}$ to rise without generating a similar rise in the productive labor force $l$, this increases the chance that conflict will result. This could occur, for example, if climatic events induced migration of rural populations into urban centers where labor markets are unable to fully absorb this influx, at least in the short to medium run, causing per capita income $\frac{\theta_{t} l}{n_{t}}$ to decline. At present, some evidence exists implicating climatic events as inducing migration of rural populations to urban centers (Barrios, Bertinelli, and Strobl (2006); BohraMishra, Oppenheimer, and Hsiang (2014); Feng, Oppenheimer, and Schlenker (2012); Feng, Krueger, and Oppenheimer (2010); Marchiori, Maystadt, and Schumacher (2012)), although there is as yet limited work linking these patters to the onset of conflict. 
Some authors have suggested that climatic conditions could alter the risk of conflict because they alter the probability that an aggressor is successful. In the context of Equation 12, a climate-induced increase in the probability of a successful attack $P_{t}$ raises the likelihood of conflict because the expected value of attacking is higher. This idea is presented in the literature in two different ways. The first interpretation is strictly logistical, i.e., climatic conditions might alter the physical environment in such a way that attacking is easier or has a greater chance of success. For example Miguel, Satyanath, and Sergenti (2004) discuss whether rainfall and floods adversely affect roads that are used to transport troops in large scale political violence, and Meier, Bond, and Bond (2007) and Ralston (2013) argue that high seasonal rainfall causes greater growth of vegetation that is used as cover for cattle raids in East Africa, giving aggressors a strategic advantage. The second interpretation is that climatic conditions might compromise an opponent's strength, increasing the likelihood that an attack is successful. This argument is usually framed as a change in "state capacity" if an incumbent government becomes militarily weaker because it has fewer economic resource to draw on, via taxation, when climatic events cause the economy to contract. In support of this notion, several analyses find that incumbent leaders face a greater risk of being removed from power following adverse climatic events (Brückner and Ciccone (2011); Burke (2012); Burke and Leigh (2010); Chaney (2013); Dell, Jones, and Olken (2012); Kim (2014)) and Shapiro et al. (2014) demonstrates that climatic events may increase voter turnout and incite aggressive demands of government services. These findings are interpreted by some authors as evidence that the climatic change weakened these leaders' power, causing $P_{t}$ (for challengers) and the risk of conflict to rise. We interpret these results as consistent with this hypothesis, although these empirical observations are not generally in disagreement with other explanations and there is no clear way to rule out alternative mechanisms in these cases, and in fact several of these authors also argue that changes in $\theta_{t}$ contribute to their findings.

Finally, climate might affect the risk of conflict because it alters the psychological rewards (or costs) of employing violence, described as $\gamma_{t}$ in Equation 12. If individuals normally have a distaste for violence, perhaps because of cultural norms or innate preferences, then $\gamma_{t}<0$. In contrast, if $\gamma_{t}>0$ then an agent derives some positive utility from the act of violence itself. If climatic conditions influence $\gamma_{t}$ by increasing the utility (or decreasing the psychological cost) of acting violently then these changes may increase the likelihood that Equation 12 is violated and conflict occurs. Studies of interpersonal violence provide the strongest suggestive evidence that a psychological mechanism is playing a role, especially in high frequency settings where there is no plausible economic or state capacity explanation linking climate to violence over very short time periods. For example, Auliciems and DiBartolo (1995) and Card and Dahl (2011) find that reports of domestic violence increase on hot days in Australia and the United States respectively, Jacob, Lefgren, and Moretti (2007) and Ranson (2014) find that assaults, rapes, and murders increase during hot weeks and months (respectively) in the United States, and Kenrick and Macfarlane (1986) find that individuals exhibit road rage with greater likelihood on hot days in a field experiment. Although detailed statistics were not reported, an early study by Rohles (1967) reported that when laboratory subjects were placed in a hot room, they 
exhibited higher rates of arguing and fighting (and even an attempted knifing in one instance) relative to a cooler treatment condition.

Gonzalez et al. (2014) make the case that changes in $\gamma_{t}$ may contribute to multiple classes of conflict in the same setting by demonstrating that elevated rates of drug cartel related killing (intergroup violence), "regular" homicide (interpersonal violence), and suicide (intrapersonal violence) in Mexico all respond to higher temperatures with similar patterns that appear unrelated to economic conditions. In support of this notion, some results suggest mechanisms through which changes in personal tastes for violence might escalate interpersonal conflicts into intergroup conflicts. For example, Larrick et al. (2011) demonstrates that during sporting events, individuals' willingness to retaliate violently against earlier violent acts committed on the field increases on hot days, and Vrij, der Steen, and Koppelaar (1994) find that police are more willing to use threatening behavior and violence for self-defense during training exercises in a laboratory when they are subject to high temperatures. If high temperatures reduce individuals' normal inhibitions against violence in response to a threat (or in retaliation to violence), then relatively small disputes between individuals might more readily escalate into costly confrontations, for instance in the case of the Mexican drug cartel violence studied in Gonzalez et al. (2014).

The above examples identify the effects of relatively short-lived changes in climatic conditions on conflict. However, findings by Prediger, Vollan, and Herrmann (2014) suggest that sustained exposure to adverse climates might also affect the likelihood of conflict through a psychological mechanism: they find that pastoralists in Namibia subject to multi-year real-world environmental scarcity are more willing to inflict harm on others in a "joy-of-destruction" laboratory game relative to comparable neighboring pastoralists that had not been subject to similar sustained scarcity.

While these patterns are strongly suggestive of the importance of psychological mechanisms, to our knowledge there is still no consensus within the psychology literature on which fundamental neurophysiological channels underpin the purported link between temperature and violence. Neural structures react to ambient temperature changes in order to regulate internal body temperature (Benzinger (1970)), but precisely which neural structures are involved in this process is poorly understood (Ray et al. (2011); Shaun Morrison (2008)). The most robust evidence lies in the role of serotonin, a neurotransmitter that facilitates body temperature regulation and is associated with aggressive behavior (Gianpaolo Basso (2000); Todd Moore (2002)). Evidence suggests that as ambient temperature rises, serotonin levels are depressed in order to regulate body temperature, and this decreased neurotransmission then leads to aggressive behavior. However, similar neurotransmitters, neuromodulators and hormones, such as testosterone, norepinephrine, cortiocotropoin releasing hormone and cholesterol, may also link temperature to violent behavior, but these pathways are understudied (Dongju Seo (2008); Richard Davidson (2000)).

\subsection{Path forward: testing by eliminating pathways}

The results above provide varying degrees of support for different pathways that may play a role in linking climatic events to conflicts. However, any single result alone is generally unable 
to definitively rule out alternative hypotheses. The central issue is that climatic conditions often affect so many aspects of an economy and society, and thus that simply matching patterns in the climate-response of both conflict and intermediary variables cannot logically reject all possible alternative explanations. In our view, some of the studies above that argue psychological pathways (via $\gamma_{t}$ ) play some role in contributing to interpersonal conflict are among the most convincing because economic conditions and most other plausible alternative mechanisms usually do not respond to the climatic conditions at the time-scale analyzed. For instance, abnormal violence committed by wealthy athletes during a professional sporting event on an exceptionally hot day (Larrick et al. (2011)) is difficult to attribute to the economic or other impacts of that hot day. Similarly, the effect of climate on weekly crime rates (e.g. Jacob, Lefgren, and Moretti (2007)) seems unlikely to be explained by economic factors, although there is some new evidence that the economic impacts of hot days may sometimes manifest quickly (eg. Deryugina and Hsiang (2014)).

We believe a fruitful path forward is to conduct direct tests of individual hypotheses (e.g., income effects) by eliminating other potential pathways and observing whether the linkage between climate and conflict persists. For example, to test the role of income effects in driving conflict, it would be useful to exploit an exogenous sources of variation that decoupled income from climate and assess whether climatic events continue to contribute to conflict risk. It is important that the potential pathway being tested is eliminated by exogenous events that are not affected by the climate nor correlated with unobserved heterogeneity between populations.

A small number of studies have begun to employ this strategy. Sarsons (2011) engages this conceptual approach, demonstrating that wage rates in Indian localities with dams are less correlated with rainfall than districts without dams, but localities with dams continue to exhibit correlations between rainfall and Hindu-Muslim riots at similar rates, suggesting that income alone is unlikely to be the key pathway linking climate to conflict in this context. We think this study is an early step in the right direction, but it is ultimately inconclusive because districts with dams may not be comparable to districts without dams in important dimensions, and because real local income and living standards may also be affected by local prices, hours worked, and the return to capital investments, all of which might be affected by rainfall and are not captured in wage rates.

Adopting a related approach, also in India, both Fetzer (2014) and Iyer and Topalova (2014) examine whether the roll-out of the large-scale Indian National Rural Employment Guarantee (NREGA) is associated with a change in the link between rainfall and conflict. The intuition is that NREGA creates a "floor" under household income for the rural poor, so the rollout of NREGA should in principle weaken the link between climate and conflict by dampening income changes. Iyer and Topalova (2014) estimate that NREGA had little effect on rainfall's impact on interpersonal conflict while Fetzer (2014) estimates that there is a substantial negative effect on rainfall-induced insurgencies. The contrasting results of these two studies is perhaps because they focus on different outcome variables and measure climate variables differently. There also remain some unresolved issues regarding the non-random placement of NREGA, especially the possibility that its roll-out correlates with other time-varying local economic, political or social 
trends. Nonetheless, we believe these two studies represent important examples of the type of empirical approach that can more conclusively identify — or rule out — the underlying mechanisms linking climate to conflict. Further work in this vein is likely to yield important insights.

\section{Discussion}

In this section, we briefly discuss three further questions that could usefully motivate future research. First, what econometric and data challenges are potentially biasing current empirical estimates of the link between climate and conflict? Second, how relevant are existing results for the long-run when societies have time to adapt to their climate? Third, and closely related, how do these results inform estimates of the future economic and social costs of climate change?

\subsection{Some remaining empirical challenges}

Various technical, economic, and data issues remain debated in the literature. One issue is that there may be serial correlation in both climate variables and conflict variables that is not fully accounted for by de-trending, and which has the potential to lead to incorrect inference if P-values are not appropriately adjusted (Bertrand, Duflo, and Mullainathan (2004)). For example, O'Loughlin et al. (2012), Lee et al. (2013), Tol and Wagner (2010), Zhang et al. (2006), Zhang et al. (2007), and Zhang et al. (2011) apply low-pass filters to their data prior to running regressions. The objective of this filtering is to allow the authors to examine gradual, low-frequency climatic changes, but this procedure induces strong serial correlation in residuals that needs to be accounted for.

A recent development in the literature is to use increasingly high resolution spatial data for large parts of the world, often using a Cartesian grid to define units of observation (e.g., Harari and La Ferrara (2013); Maystadt, Calderone, and You (2014); O'Loughlin et al. (2012); Theisen, Holtermann, and Buhaug (2011)). This approach is designed to allow researchers to observe spatially fine-grained structures in the response of conflict to climate. For example, Harari and La Ferrara (2013) are able obtain estimates for the average spatio-temporal lag structure in the response across African "pixels". However, an important unresolved concern with this approach in general is that the underlying climate data used by these studies may not actually be as finely resolved as the grid density might suggest, often relying on the interpolation of observations or lower resolution weather models (see Auffhammer et al. (2013)). This issue is particularly pronounced in remote regions where government data collection presence may be minimal, the same types of regions where conflict may be more likely to occur.

Figure 8, reproduced from Hsiang et al. (2013c), illustrates this point. The left panel overlays the spatial distribution and completeness of rainfall observations with a map of civil war onset locations studied in Theisen, Holtermann, and Buhaug (2011). The right panel displays the completeness of these records at the conflict locations of interest. Note that most conflict locations of interest have zero rainfall observations during the period of study, and no location of interest has a complete record - implying that most of the statistical analysis relies on interpo- 
lated data. Thus, we caution that research using high resolution gridded data may overstate the quality of information actually contained in the dataset. To our knowledge, the extent of this error has not been formally characterized and its impact on regression estimates is not known. To the extent that these errors are classical in the most high resolution data-or at least mean zero in expectation-it is likely that average measurement error is smaller for more aggregated variables (e.g., average temperature in an entire country) because positive and negative errors will partially cancel each other out. Future work could usefully attempt to characterize the extent and importance of this issue.

Finally, climatic events may have different spatial extent and it remains unknown whether spatial structure in climatic events matters. Different types of conflict have been shown to respond to climatic events with different spatial and temporal scales (Hsiang, Burke, and Miguel (2013a)), for example recall Figure 1. Yet it is unknown if the spatial extent of a climatic anomaly has a causal effect on the likelihood that the event triggers conflict. In cases where societies sometimes cope with climatic disturbances through trade or migration, the spatial scale of an event could plausibly determine whether these strategies are viable options for mitigating this risk.

\subsection{Adaptation to Climate}

The extent to which populations might adapt to climatic conditions, thereby dampening the effect of climate on conflict, remains widely debated. As discussed earlier, econometric concerns regarding unobservable heterogeneity across space motivates panel data research designs that exploit local time-series variation in climatic conditions. This approach allows insight into climate's effect on when conflict occurs in a location, but it does not allow us to infer whether climatic conditions influence where conflict will occur on average. If societies successfully and fully adapt to their average conditions in the long run, then no society would exhibit conflicts that are attributable to their average climate, but perturbations from that average may still cause conflicts. However, if societies do not adapt effectively even in the long run, the same mechanisms that generate conflicts from temporary climate changes may also permanently alter conflict rates if a society is exposed to a permanently different climate.

The ideal thought experiment in this context is to relocate an entire population from a cold climate, such as Norway, to a hot climate, such as Nigeria, and observe whether rates of conflict adjust to be nearer to the rates originally observed in Nigeria. The frequency-identification tradeoff discussed previously, as well as geographical constraints, makes empirical study of this problem fundamentally difficult. Nonetheless, determining if populations can and do adapt to climate is central to assessing whether the effects identified through the panel data approach we describe in Section 2 above can be interpreted as having explanatory power both in the cross-section and into the distant future.

Two distinct approaches have been used to understand if populations adapt to climatic events after being exposed to particular climatic conditions for substantial lengths of time, and although both are useful neither provides entirely definitive answers. The first approach exploits high-frequency climatic events and identifies heterogeneous effects for populations in 
different climates. The underlying idea is that if populations have adapted to a particular climate (i.e., a hot climate), then they might become less vulnerable to short term changes in climate (i.e., hotter than average temperatures). For example, Ranson (2014) and Rotton and Cohn (2000) test whether hot days in hotter U.S. locations, such as Dallas, produce similar impacts on interpersonal conflict as hot days in cooler locations, such as Minneapolis, and finds that impacts are in fact similar. This result cannot prove that communities do not adapt to long-term climate conditions, since the identifying variation is all short-term; however, it does suggest that long term exposure need not always lead to more effective short-term adaptation.

The second approach to understanding adaptation examines long term climatic variation directly. For example, Bai and Kung (2010) and Anderson, Johnson, and Koyama (2013) look at the effect of decade-long average climate on conflict in China and Europe, respectively. Changes in decadal averages requires that climatic events are sustained over time, and thus these analyses describe how societies cope with long-term shifts in climate. Data are a major challenge with this approach: large samples with multiple decade-long observational periods are required, so the data must by necessity stretch far backward in time. For instance, Bai and Kung (2010) are able to examine decades between 220-1839 AD, but these type of data are obviously lacking for most settings. Nevertheless, these studies generally find that sustained shifts in climate are associated with changes in various forms of conflict, indicating that populations do not fully adapt to decade-long climatic changes. Yet because these analyses stretch so far back in time, it is not clear whether the societies studied provide valid comparisons for modern societies. Hsiang and Burke (2013) point out that these historical societies might be reasonable proxies for some populations today because their average per capita income is similar to average income in many low income countries today, but the technological frontier and possible trading partners available to modern low income economies are clearly very different from those faced centuries ago.

A related approach, which has not yet been widely implemented in the literature but which we believe holds promise, is to study how gradual trends in conflict and gradual trends in climate are correlated over time across locations. This "long difference" empirical approach is employed in Burke and Emerick (2013) to demonstrate that the effects of climate changes on agriculture in the U.S. over the course of multiple decades mirror estimates derived from the high-frequency annual time series approach in Equation 3.

To demonstrate how this approach can be applied to the study of conflict, we implement a new analysis here using pixel-level data on a comprehensive measure of local conflict in East Africa (1991-2009) from O'Loughlin et al. (2012). We first compute gradual trends in conflict for each pixel and gradual trends in temperature for each pixel by differencing average values between the period 1991-1995 and the period 2005-2009. Trends in local temperature are shown in the left panel of Figure 9, and range from pixels with no warming to pixels with more than $2{ }^{\circ} \mathrm{C}$ warming. We then regress the change in local conflict on the change in local climate at the pixel level. In the right panel of Figure 9 we compare the point estimate from this long difference regression with the point estimate obtained using the high frequency panel data approach in Equation 3. Similar to Burke and Emerick (2013), this long difference estimate is nearly identical to the annual panel estimate, suggesting that these communities do not exhibit 
effective adaptation to climate change over this 20 year period. We also display the point estimate when we use even longer difference periods of 1991-1999 and 2001-2009, and find that the estimated effect actually becomes somewhat larger in magnitude (rather than smaller, which would be the case if there were partial adaptation over time), although we note that the effect is less precisely estimated and not statistically different from the other two estimates.

The pattern in Figure 9 indicates that, at least in the context of local conflict in East Africa, short run changes in climate are closely related to the effect of longer term and more gradual shifts in climate. To our knowledge, no study has characterized the degree of adaptation to climate in terms of conflict outcomes in this way. Further analyses using a similar empirical approach will help provide important insight into whether, when, and how societies can adapt to gradual climatic changes in other contexts, and such studies are a top priority for future research. Given the quantitatively large effect of current climate on conflict, it appears that future adaptation will need to be dramatic if it is to offset the potentially large adverse effect of future climate on conflict.

\subsection{Implications for Global Climate Change}

The above evidence makes a prima facie case that future anthropogenic climate change could worsen conflict outcomes across the globe in comparison to a future with no climatic changes, given the large expected increase in global surface temperatures and the likely increase in the variability of precipitation across many regions over coming decades (Field (2012); Stocker et al. (2013)). Recalling our finding that a $1 \sigma$ rise in a location's temperature is associated with an average $2.1 \%$ net increase in the rate of interpersonal conflict and a $11.3 \%$ increase in the rate of intergroup conflict, and assuming that future societies will respond to climatic shifts in ways similar to current societies, one can calibrate the potential effect of anthropogenic global warming by rescaling expected temperature changes according to each location's historical variability. Hsiang, Burke, and Miguel (2013a) rescale expected warming by 2050, computed as the ensemble mean for 21 climate models running the A1B emissions scenario (which is now thought to be conservative regarding future carbon emissions), in terms of location-specific standard deviations (Meehl et al. (2007)). Almost all inhabited locations are projected to warm by at least $2 \sigma$, with the largest increases exceeding $4 \sigma$ in tropical regions that are already warm and also currently experience relatively low inter-annual temperature variability. These large predicted climatological changes, combined with the quantitatively large effect of climate on conflict - particularly intergroup conflict - suggest that amplified rates of human conflict could represent a large and critical impact of anthropogenic climate change.

The magnitude of these back-of-the-envelope estimates provides some intuition for the potential change in conflict one might expect, but policy design requires more careful projections of potential impacts. Burke et al. (2014) point out that projections of potential impacts should account for uncertainty in the structure and magnitude of warming that will be observed under a given policy, in addition to statistical uncertainty in the parameter estimates relating historical climate to conflict. This approach is adopted in two studies that make probabilistic projections for changes in the rate of future conflict attributable to climate change. Burke et al. 
(2009) use their estimates (which are slightly larger than the mean estimated conflict impact $\mu$ generated in the meta-analysis above) to project the incidence of civil wars and associated battle-related deaths in Africa under a "business as usual" scenario ${ }^{5}$. Accounting for uncertainty in the global climate response, Burke et al. (2009) estimate that warming will increase armed conflict incidence by $54 \%$ in the coming decades (95\% CI of $6 \%-119 \%$ increase). If future civil conflicts remain as deadly as those that took place recently, then they project that this increase in conflict would result in 393,000 additional battle deaths by 2030 .

Houser et al. (forthcoming) conduct a meta-analysis of the nonlinear responses for violent crime and property crime to the distribution of daily temperatures in the United States. Then using the posterior response function, they project future changes in crime attributable to three warming scenarios ${ }^{6}$ using the distribution of 400 model-derived climate projections for each county in each scenario. Figure 10 is reproduced using results from Houser et al. (forthcoming) and demonstrates the spatial distribution and probability distribution of nationally aggregated changes to violent crime rates. Ceteris paribus, Houser et al. (forthcoming) estimate that nationally averaged crime rates will rise 1.7-5.4\% (median: $3 \%$ ) by end of century under a "business as usual" warming scenario. Applying valuations to specific types of crime from a meta-analysis by Heaton (2010), Houser et al. (forthcoming) estimate that these additional interpersonal conflicts would have a social cost of roughly $\$ 5$-20 billion if they occurred in today's economy, a loss near but slightly less than their median projection for economic costs incurred through agricultural impacts. The bottom line is that the adverse impact of global climate change on both conflict outcomes themselves, and on resulting economic outcomes, may be large.

These projections for changes in conflict due to climate change capture only the partial effect of climate, and the overall trend in conflict will also certainly be affected by non-climate factors. For example, if crime rates are expected to decline in the future because of (say) improved enforcement technologies and rising incomes, then the projected positive impact of future global warming on crime in the U.S. must be considered together with these other effects. It is clearly possible that overall conflict rates will decline in the future, even if warming causes an upward trend in conflict relative to a counterfactual with no warming. Any projected impact of climate change must be considered along with these other trends.

\section{Conclusion}

In this article, we survey and summarize the new and rapidly expanding economic literature on the links between climate and conflict. The question of the linkage between climate and conflict has been widely and inconclusively debated in other disciplines for many years, mainly using qualitative or case study methods. Findings from the growing body of rigorous research in economics, as well as from political science and other disciplines that use modern econometric analytical approaches, indicate that adverse climatic events increase the risk of violence and

\footnotetext{
${ }^{5}$ Burke et al. (2009) use the A1B scenario for models in CMIP3, a multi-model dataset compiled from climate model output contributed by major modeling centers between 2005 and 2006.

${ }^{6}$ Houser et al. (forthcoming) use the Representative Concentration Pathways (RCPs) from CMIP5, so their "business as usual" scenario is RCP8.5.
} 
conflict, at both the interpersonal level and the intergroup level, in societies around the world and throughout history.

The median effect of a $1 \sigma$ change in climate variables is a $14 \%$ change in the risk of intergroup conflict and a $4 \%$ change in interpersonal violence, across the studies that we review where it is possible to calculate standardized effects. In our separate meta-analyses of the contemporaneous and lagged effects of temperature and rainfall, we find that contemporaneous temperature has the largest average effect by far (intergroup conflict: $2.4 \% / \sigma$, interpersonal conflict: $11.3 \% / \sigma$ ) but that the cumulative effect of rainfall on intergroup conflict is also substantive $(3.5 \% / \sigma)$. If future responses to climate are similar to these past responses, then anthropogenic climate change has the potential to substantially increase global violent crime, civil conflict and political instability, relative to a world without climate change. This finding of course does not imply, nor do we conclude, that climate is the sole or even the primary driving force behind human conflict. However, we do conclude that large variations in climate can have large impacts on the incidence of conflict and violence across a variety of contexts.

We identify many open research questions and productive avenues for future investigation in this literature. Achieving a better understanding of the mechanisms - both economic and non-economic, including possible psychological channels - underlying the link between extreme climate and conflict is arguably the most important and fruitful direction for future work. In this emphasis on research regarding mechanisms, we echo the conclusion in Dell, Jones \& Olken's recent review of existing research on the links between climate and economic performance, in which conflict may play an important role (Dell, Jones, and Olken (2013)).

It seems likely that climatic changes influence conflict through multiple pathways that may differ between contexts. There is considerable suggestive evidence that economic factors are important mechanisms, especially in low income settings where extreme climate often quite directly affects economic conditions through agriculture. The strong link between temporary high temperatures and short-run increases in crime in wealthier societies provides evidence that non-economic factors, perhaps working through individual psychology, are also important. In other settings, the combination and interaction of economic, social, political, and psychological factors might be critical.

To place the state of the existing body of research on climate and conflict in perspective, it is worth recalling that statistical analyses identified the smoking of tobacco as a proximate cause of lung cancer by the 1930's (Witschi (2001)), although the research community was unable to provide a detailed account of the mechanisms explaining the linkage until decades later. So although future research will be critical in pinpointing precisely why and how climate affects human conflict across different settings, disregarding the potential effect of anthropogenic climate change on human conflict in the interim is, in our view, a dangerously misguided interpretation of the available evidence.

The lack of a single, simple causal pathway linking climate and conflict does not imply that there is a lack of evidence that a causal relationship exists, but it does urge caution when applying these econometric estimates to either policy prescriptions or to future global warming scenarios. Nonetheless, identifying key causal pathways is a research objective that holds great 
promise, as the policies and institutions necessary to reduce conflict can only be designed if we understand why conflicts arise in particular contexts. The success of such institutions will be increasingly important in the coming decades as changes in climatic conditions amplify the risk of human conflicts, and as the need for effective adaptation to climate becomes increasingly important.

\section{References}

Anderson, C.A, K.B Anderson, N Dorr, K.M DeNeve, and M Flanagan. 2000. "Temperature and aggression." Advances in Experimental Social Psychology 32:63-133.

Anderson, C.A, B.J Bushman, and R.W Groom. 1997. "Hot years and serious and deadly assault: Empirical tests of the heat hypothesis." Journal of Personality and Social Psychology $73(6): 1213$.

Anderson, R Warren, Noel D Johnson, and Mark Koyama. 2013. "From the Persecuting to the Protective State? Jewish Expulsions and Weather Shocks from 1100 to 1800." Working paper URL http://ssrn. com/abstract=2212323.

Angrist, Joshua D. and Jorn-Steffen Pischke. 2008. Mostly Harmless Econometrics: An Empiricist's Companion. Princeton University Press.

Anttila-Hughes, Jesse K. and Solomon M. Hsiang. 2012. "Destruction, Disinvestment, and Death: Economic and Human Losses Following Environmental Disaster." Working paper URL http://papers.ssrn.com/abstract_id=2220501.

Arezki, R and M Brueckner. 2104. "Effects of International Food Price Shocks on Political Institutions in Low-Income Countries: Evidence from and International Food Net-Export Price Index." World Development 61:142-153.

Auffhammer, Maximilian, Solomon Hsiang, Wolfram Schlenker, and Adam Sobel. 2013. "Using Weather Data and Climate Model Output in Economic Analyses of Climate Change." Review of Environmental Economics and Policy 7 (2).

Auliciems, A and L DiBartolo. 1995. "Domestic violence in a subtropical environment: police calls and weather in Brisbane." International Journal of Biometeorology 39 (1):34-39.

Bai, Y and J.K Kung. 2010. "Climate Shocks and Sino-nomadic Conflict." The Review of Economics and Statistics (0).

Barrios, S, L Bertinelli, and E Strobl. 2006. "Climatic change and rural-urban migration: The case of Sub-Saharan Africa." Journal of Urban Economics 60 (3):357-371.

- 2010. "Trends in rainfall and economic growth in Africa: A neglected cause of the African growth tragedy." The Review of Economics and Statistics 92 (2):350-366.

Bellemare, M. Forthcoming. "Rising Food Prices, Food Price Volatility and Social Unrest." $A J A E$.

Benzinger, T. H. 1970. "Peripheral Cold Reception and Central Warm Reception, Sensory Mechanisms of Behavioural and Automatic Thermostasis." In Physiological and Behavioural Temperature Regulation, edited by J. A. J. Stolwijk A. P. Gagge, J. F. Hardy. Thomas.

Bergholt, D and P Lujala. 2012. "Climate-related natural disasters, economic growth, and armed civil conflict." Journal of Peace Research 49 (1):147-162.

Berman, E, J H Felter, and J N Shapiro. 2011. "Do Working Men Rebel? Inusrgency and Unemployment in Afghanistan, Iraq and the Philippines." Journal of Conflict Resolution $55(4): 496-528$.

Berman, E, J.N Shapiro, and J.H Felter. 2011. "Can hearts and minds be bought? the economics of counterinsurgency in Iraq." Journal of Political Economy 119 (4):766. 
Bertrand, Marianne, Esther Duflo, and Sendhil Mullainathan. 2004. "How Much Should We Trust Differences-in-Differences Estimates?" The Quarterly Journal of Economics 119 (1):249-275.

Blakeslee, D and R Fishman. 2014. "Weather Shocks, Crime, and Agriculture: Evidence from India." Working paper .

Blattman, Christopher and Edward Miguel. 2010. "Civil War." Journal of Economic Literature

Bohlken, A. T and E. J Sergenti. 2010. "Economic growth and ethnic violence: An empirical investigation of Hindu-Muslim riots in India." Journal of Peace Research 47 (5):589-600.

Bohra-Mishra, Pratikshya, Michael Oppenheimer, and Solomon M. Hsiang. 2014. "Nonlinear permanent migration responses to climatic variations but minimal response to disasters." Proceedings of the National Academy of Sciences 111 (27):9780-9785.

Brodeur, Abel, Mathias Lé, Marc Sangnier, and Yanos Zylberberg. 2013. "Star wars: The empirics strike back." Tech. rep., Discussion Paper Series, Forschungsinstitut zur Zukunft der Arbeit.

Brückner, M and A Ciccone. 2011. "Rain and the democratic window of opportunity." Econometrica 79 (3):923-947.

Buckley, B.M, K.J Anchukaitis, D Penny, R Fletcher, E.R Cook, M Sano, L.C Nam, A Wichienkeeo, T.T Minh, and T.M Hong. 2010. "Climate as a contributing factor in the demise of Angkor, Cambodia." PNAS 107 (15):6748.

Buhaug, H. 2010a. "Climate not to blame for African civil wars." Proceedings of the National Academy of Sciences .

. 2010b. "Reply to Burke et al.: Bias and climate war research." Proceedings of the National Academy of Sciences 107 (51):E186-E187.

Buhaug, H, H Hegre, and H Strand. 2010. "Sensitivity analysis of climate variability and civil war." PRIO working paper URL http://www.prio.no/CSCW/Research-and-Publications/ Publication/?oid=193994.

Burke, M. B, E Miguel, S Satyanath, J. A Dykema, and D. B Lobell. 2010a. "Climate robustly linked to African civil war." PNAS 107 (51):E185-E185.

. 2010b. "Reply to Sutton et al.: Relationship between temperature and conflict is robust." Proceedings of the National Academy of Sciences 107 (25):E103-E103.

Burke, Marshall, John Dykema, David Lobell, Edward Miguel, and Shanker Satyanath. 2010c. "Climate and civil war: is the relationship robust?" NBER working paper 16440 URL http: //www. nber .org/papers/w16440.

Burke, Marshall, John Dykema, David B Lobell, Edward Miguel, and Shanker Satyanath. 2014. "Incorporating Climate Uncertainty into Estimates of Climate Change Impacts." Review of Economics and Statistics (0).

Burke, Marshall and Kyle Emerick. 2013. "Adaptation to Climate Change: Evidence from US Agriculture." Working paper URL http://ssrn.com/abstract=2144928.

Burke, Marshall, Erick Gong, and Kelly Jones. 2014. "Income shocks and HIV in Africa." The Economic Journal.

Burke, Marshall, Solomon M. Hsiang, and Edward Miguel. 2014. "Temperature and Witchkilling." Working paper .

Burke, M.B., E. Miguel, S. Satyanath, J.A. Dykema, and D.B. Lobell. 2009. "Warming increases the risk of civil war in Africa." Proceedings of the National Academy of Sciences 106 (49):20670.

Burke, Paul J. 2012. "Economic Growth and Political Survival." The B.E. Journal of Macroeconomics 12 (1). 
Burke, Paul J and Andrew Leigh. 2010. "Do Output Contractions Trigger Democratic Change?" American Economic Journal: Macroeconomics 2 (4):124-157.

Bushman, B.J, M.C Wang, and C.A Anderson. 2005. "Is the curve relating temperature to aggression linear or curvilinear? A response to Bell (2005) and to Cohn and Rotton (2005)." Journal of Personality and Social Psychology .

Card, David and Gordon B Dahl. 2011. "Family Violence and Football: The Effect of Unexpected Emotional Cues on Violent Behavior." The Quarterly Journal of Economics $126(1): 103-143$.

Card, David and Alan B Krueger. 1995. "Time-series minimum-wage studies: a meta-analysis." The American Economic Review 85 (2):238-243.

Caruso, R, I Petrarca, and R Ricciuti. 2014. "Climate Change, Rice Crops and Violence: Evidence from Indonesia." CESifo Working Paper (4665).

Cervellati, Matteo, Uwe Sunde, and Simona Valmori. 2011. "Disease Environment and Civil Conflicts." IZA DP No. 5614 URL http://papers. ssrn. com/abstract=1806415.

Chaney, E. 2013. "Revolt on the Nile: Economic Shocks, Religion and Political Influence." Econometrica URL http://scholar.harvard.edu/chaney/files/nile.pdf.

Chassang, S. and G. Padro-i-Miquel. 2009. "Economic shocks and civil war." Quarterly Journal of Political Science 4 (3):211-228.

Ciccone, Antonio. 2011. "Economic Shocks and Civil Conflict: A Comment." American Economic Journal: Applied Economics 3:1-14.

Cohn, Ellen and James Rotton. 1997. "Assault as a function of time and temperature: A moderator-variable time-series analysis." Journal of Personality and Social Psychology $72(6): 1322$.

Couttenier, Mathieu and Raphael Soubeyran. 2013. "Drought and Civil War in Sub-Saharan Africa." Economic Journal .

Crost, B, J H Felter, and P Johnston. 2014. "Conditional Cash Transfers, Civil Conflict and Insurgent Influence: Experimental Evidence from the Philippines." HiCN Working Paper (174).

Cullen, H, P Demenocal, S Hemming, G Hemming, F Brown, T Guilderson, and F Sirocko. 2000. "Climate change and the collapse of the Akkadian empire: Evidence from the deep sea." Geology 28 (4):379.

Davis, Mike. 2001. Late Victorian holocausts: El Niño famines and the making of the third world. Verso Books.

Dell, Melissa. 2012. "Path dependence in development: Evidence from the Mexican Revolution." Working paper .

Dell, Melissa, Benjamin F. Jones, and Benjamin A. Olken. 2012. "Climate Change and Economic Growth: Evidence from the Last Half Century." American Economic Journal: Macroeconomics .

Dell, Melissa, Benjamin F Jones, and Benjamin A Olken. 2013. "What do we learn from the weather? The new climate-economy literature." Tech. rep., Journal of Economic Literature.

DeMenocal, P.B. 2001. "Cultural responses to climate change during the late Holocene." Science 292 (5517):667-673.

Deryugina, Tatyana and Solomon M. Hsiang. 2014. "Does the environment still matter? Temperature and income in the United States." Working paper .

Diamond, Jared. 2005. Collapse: How societies choose to fail or succeed. Penguin.

Disdier, Anne-Célia and Keith Head. 2008. "The puzzling persistence of the distance effect on bilateral trade." The Review of Economics and Statistics 90 (1):37-48. 
Dongju Seo, Patrick Kennealy, Christopher Patrick. 2008. "Role of Serotonin and Dopamine System Interactions in the Neurobiology of Impulsive Aggression and its Comorbidity with Other Clinical Disorders." Aggression and Violent Behavior 13 (5):383-395.

Dube, O and J Vargas. 2012. "Commodity price shocks and civil conflict: Evidence from Colombia." Review of Economic Studies, forthcoming .

Fagan, Brian M. 2000. The Little Ice Age: how climate made history, 1300-1850. Basic Books.

Feng, S., M. Oppenheimer, and W. Schlenker. 2012. "Climate Change, Crop Yields, and Internal Migration in the United States." .

Feng, Shuaizhang, Alan B. Krueger, and Michael Oppenheimer. 2010. "Linkages among climate change, crop yields and Mexico-US cross-border migration." Proceedings of the National Academy of Sciences 107 (32):14257-14262.

Fetzer, T. 2014. "Can Workfare Programs Moderate Violence? Evidence from India." Working paper.

Field, Christopher B. 2012. Managing the risks of extreme events and disasters to advance climate change adaptation: Special report of the Intergovernmental Panel on Climate Change. Cambridge University Press.

Fjelde, H. and N. von Uexkull. 2012. "Climate triggers: Rainfall anomalies, vulnerability and communal conflict in sub-Saharan Africa." Political Geography .

Franco, Annie, Neil Malhotra, and Gabor Simonovits. 2014. "Publication Bias in the Social Sciences: Unlocking the File Drawer." Science 345 (6203):1502-1505.

Freedman, D.A. 1991. "Statistical models and shoe leather." Sociological methodology 21:291313.

Gelman, Andrew, John B Carlin, Hal S Stern, and Donald B Rubin. 2004. Bayesian data analysis. Chapman \& Hall/CRC.

Gerber, Alan and Neil Malhotra. 2008a. "Do statistical reporting standards affect what is published? Publication bias in two leading political science journals." Quarterly Journal of Political Science 3 (3):313-326.

Gerber, Alan S and Neil Malhotra. 2008b. "Publication bias in empirical sociological research: Do arbitrary significance levels distort published results?" Sociological Methods 83 Research .

Gianpaolo Basso, Mario Guazzelli Karen Jaffe Pietro Pietrini, Jordan Grafman. 2000. "Neural Correlates of Imaginal Aggressive Behavior Assessed by Positron Emission Tomography in Healthy Subjects." American Journal of Psychiatry 11:1772-1781.

Gleditsch, N. 2012. "Whither the weather? Climate change and conflict." Journal of Peace Research .

Gonzalez, Felipe, C. Baysan, M. Burke, S. Hsiang, and E. Miguel. 2014. "Economic and noneconomic factors in violence: Evidence from drug-cartels, suicides, and climate in Mexico." Working paper .

Graff Zivin, Joshua and M Neidell. 2013. "Temperature and the Allocation of Time: Implications for Climate Change." Journal of Labor Economics .

Grove, R. 2007. "The Great El Niño of 1789-93 and its Global Consequences: Reconstructing an an Extreme Climate Event in World Environmental History." The Medieval History Journal

Harari, Mariaflavia and Eliana La Ferrara. 2013. "Conflict, Climate and Cells: A disaggregated analysis." Working paper URL http://www-2.iies.su.se/Nobe12012/Papers/LaFerrara_ Harari.pdf.

Haug, G.H, D Günther, L.C Peterson, D.M Sigman, K.A Hughen, and B Aeschlimann. 2003. "Climate and the collapse of Maya civilization." Science 299 (5613):1731.

Heaton, Paul. 2010. Hidden in Plain Sight. RAND Corporation. 
Hendrix, C. S and I Salehyan. 2012. "Climate change, rainfall, and social conflict in Africa." Journal of Peace Research 49 (1):35-50.

Hidalgo, F.D, S Naidu, S Nichter, and N Richardson. 2010. "Economic determinants of land invasions." The Review of Economics and Statistics 92 (3):505-523.

Holland, Paul W. 1986. "Statistics and Causal Inference." Journal of the American Statistical Association 81:945-960.

Homer-Dixon, Thomas F. 1999. Environment, Scarcity and Violence. Princeton University Press.

Houser, Trevor, Robert Kopp, Solomon M. Hsiang, Michael Delgado, Amir Jina, Kate Larsen, Michael Mastrandrea, Shashank Mohan, Robert Muir-Wood, DJ Rasmussen, James Rising, and Paul Wilson. forthcoming. American Climate Prospectus: Economic Risks in the United States. Columbia University Press.

Hsiang, S.M., K.C. Meng, and M.A. Cane. 2011. "Civil conflicts are associated with the global climate." Nature 476 (7361):438-441.

Hsiang, Solomon M. 2010. "Temperatures and Cyclones strongly associated with economic production in the Caribbean and Central America." Proceedings of the National Academy of Sciences 107 (35):15367-15372.

- 2012. "Visually-Weighted Regression." Working paper URL http://papers.ssrn. $\mathrm{com} /$ sol3/papers. cfm?abstract_id=2265501.

Hsiang, Solomon M. and Marshall Burke. 2013. "Climate, conflict, and social stability: what does the evidence say?" Climatic Change.

Hsiang, Solomon M., Marshall Burke, and Edward Miguel. 2013a. "Quantifying the Influence of Climate on Human Conflict." Science.

32

2013b. "Reconciling Temperature-conflict Results in Kenya." CEGA Working Paper

. 2014. "Reconciling climate-conflict meta-analyses: reply to Buhaug et al." Climatic Change.

Hsiang, Solomon M., Marshall Burke, Edward Miguel, Mark A. Cane, and Kyle C. Meng. 2013c. "Analysis of Statistical Power Reconciles Climate-Conflict Results in Africa." working paper

Hsiang, Solomon M. and Kyle C. Meng. 2014. "Reconciling disagreement over climate-conflict results in Africa." Proceedings of the National Academy of Sciences .

Huntington, Ellsworth. 1917. "Climatic change and agricultural exhaustion as elements in the fall of Rome." The Quarterly Journal of Economics 31 (2):173-208.

Iyengar, R, J Monten, and M Hanson. 2011. "Building Peace: The Impace of Aid on the Labor Market for Insurgents." Working paper .

Iyer, L and P Topalova. 2014. "Poverty and Crime: Evidence from Rainfall and Trade Shocks in India." Working paper .

Jacob, B, L Lefgren, and E Moretti. 2007. "The dynamics of criminal behavior: Evidence from weather shocks." The Journal of Human Resources .

Jia, Ruixue. 2013. "Weather Shocks, Sweet Potatoes and Peasant Revolts in Historical China." Economic Journal, forthcoming .

Jones, Benjamin and Benjamin Olken. 2010. "Climate shocks and exports." American Economic Review: Papers and Proceedings 100:454-459.

Kenrick, D. T and S. W Macfarlane. 1986. "Ambient Temperature and Horn Honking: A Field Study of the Heat/Aggression Relationship." Environment and Behavior 18 (2):179-191. 
Kim, N. K. 2014. "Revisiting Economic Shocks and Coups." Journal of Conflict Resolution $: 1-29$.

Kung, James Kai-sing and Chicheng Ma. 2012. "Can Cultural Norms Reduce Conflicts? Confucianism and Peasant Rebellions in Qing China." Working paper URL http://ahec2012. org/papers/S6B-2_Kai-singKung_Ma.pdf.

Kuper, R and S Kröpelin. 2006. "Climate-controlled Holocene occupation in the Sahara: motor of Africa's evolution." Science 313 (5788):803.

Larrick, Richard P., Thomas A. Timmerman, Andrew M. Carton, and Jason Abrevaya. 2011. "Temper, Temperature, and Temptation: Heat-Related Retaliation in Baseball." Psychological Science 22:423-428.

Lee, Harry F, David D Zhang, Peter Brecke, and Jie Fei. 2013. "Positive correlation between the North Atlantic Oscillation and violent conflicts in Europe." Climate Research 56:1-10.

Levy, M.A, C Thorkelson, C Vörösmarty, E Douglas, M Humphreys, and N Hampshire. 2005. "Freshwater availability anomalies and outbreak of internal war: Results from a global spatial time series analysis." International workshop on 'Human Security and Climate Change', Holmen, Norway URL http://www.ciesin.columbia.edu/pdf/waterconflict.pdf.

Levy, Mark A. 1995. "Is the Environment a National Security Issue?" International Security 20:35-62.

Lobell, David B., Wolfram Schlenker, and Justin Costa-Roberts. 2011. "Climate Trends and Global Crop Production Since 1980." Science 333 (6042):616-620.

Marchiori, L, J.F Maystadt, and I Schumacher. 2012. "The impact of weather anomalies on migration in sub-Saharan Africa." Journal of Environmental Economics and Management .

Mares, Dennis. 2013. "Climate change and levels of violence in socially disadvantaged neighborhood groups." Journal of Urban Health :1-16.

Maystadt, J, M Calderone, and L You. 2014. "Local Warming and Violent Conflict in North and South Sudan." Journal of Economic Geography (335).

Maystadt, J and O Ecker. 2014. "Extreme Weather and Civil War in Somalia: Does Drought Fuel Conflict in Somalia through Livestock Price Shocks?" American Journal of Agricultural Economics .

Meehl, Gerald A., Curt Covey, Thomas Delworth, Mojib Latif, Bryant McAvaney, John F. B., Mitchell, Ronald J. Stouffer, and Karl E. Taylor. 2007. "The WCRP CMIP3 Multimodel Dataset: A New Era in Climate Change Research." Bulletin of the American Meterological Society 88:1383-1394.

Mehlum, H, E Miguel, and R Torvik. 2006. "Poverty and crime in 19th century Germany." Journal of Urban Economics 59 (3):370-388.

Meier, Patrick, Doug Bond, and Joe Bond. 2007. "Environmental influences on pastoral conflict in the Horn of Africa." Political Geography 26:716-735.

Miguel, E. 2005. "Poverty and witch killing." Review of Economic Studies 72 (4):1153-1172.

Miguel, E., S. Satyanath, and E. Sergenti. 2004. "Economic Shocks and Civil Conflict: An Instrumental Variables Approach." Journal of Political Economy 112 (4):725-753.

Miguel, Edward and Shanker Satyanath. 2011. "Re-examining Economic Shocks and Civil Conflict." American Economic Journal: Applied Economics 3:1-6.

O'Loughlin, J, F Witmer, A Linke, A Laing, A Gettelman, and J Dudhia. 2012. "Climate variability and conflict risk in East Africa, 1990-2009." Proc. Natl. Acad. Sci. USA .

Prediger, Sebastian, Bj orn Vollan, and Benedikt Herrmann. 2014. "Resource scarcity and antisocial behavior." Journal of Public Economics 119 (1):1-9. 
Ralston, Laura Rosalind. 2013. Essays on conflict, cooperation and economic development. Ph.D. thesis, Massachusetts Institute of Technology.

Ranson, Matthew. 2014. "Crime, weather, and climate change." Journal of Environmental Economics and Management 67 (3):274-302.

Ray, Russell S, Andrea E Corcoran, Rachael D Brust, Jun Chul Kim, George B Richerson, Eugene Nattie, and Susan M Dymecki. 2011. "Impaired respiratory and body temperature control upon acute serotonergic neuron inhibition." Science 333 (6042):637-642.

Richard Davidson, Christine Larson, Katherine Putnam. 2000. "Dysfunction in the Neural Circuitry of Emotion Regulation: A Possible Prelude to Violence." Science 289.

Rohles, Frederick H. 1967. "Environmental psychology - bucket of worms." Psychology today 1 (2):54-63.

Rosenthal, Robert. 1979. "The file drawer problem and tolerance for null results." Psychological bulletin $86(3): 638$.

Rotton, James and Ellen Cohn. 2000. "Violence is a curvilinear function of temperature in Dallas: A replication." Journal of Personality and Social Psychology 78 (6):1074.

Salehyan, Idean and Cullen Hendrix. 2012. "Climate Shocks and Political Violence." Annual Convention of the International Studies Association :1-33.

Sarsons, H. 2011. "Rainfall and Conflict." Harvard working paper URL http://www.econ. yale.edu/conference/neudc11/papers/paper_199.pdf.

Scheffran, Jürgen, Michael Brzoska, Hans Günter Brauch and Peter Michael Link, and Janpeter Schilling, editors. 2012. Climate Change, Human Security and Violent Conflict: Challenges for Societal Stability, vol. 8. Springer Verlag.

Schlenker, W and D Lobell. 2010. "Robust negative impacts of climate change on African agriculture." Environmental Research Letters .

Schlenker, Wolfram and Michael Roberts. 2009. "Nonlinear temperature effects indicate severe damages to U.S. crop yields under climate change." Proceedings of the National Academy of Sciences 106 (37):15594-15598.

Sekhri, Sheetal and Adam Storeygard. 2012. "Dowry Deaths: Consumption Smoothing in Response to Climate Variability in India." Working paper .

Shapiro, J N, C Fair, P Kuhn, and N Malhotra. 2014. "Economic Shocks and Civic Engagement: Evidence from the 2010-11 Pakistani Floods." Working paper .

Shaun Morrison, Christopher Madden, Kazuhiro Nakamura. 2008. "Central Control of Thermogenesis in Mammals." Experimental Physiology 93:773-797.

Stocker, Thomas F, Dahe Qin, Gian-Kasper Plattner, Melinda Tignor, Simon K Allen, Judith Boschung, Alexander Nauels, Yu Xia, Vincent Bex, Pauline M Midgley et al. 2013. Climate Change 2013. The Physical Science Basis. Working Group I Contribution to the Fifth Assessment Report of the Intergovernmental Panel on Climate Change. Cambridge University Press.

Sutton, A. E, J Dohn, K Loyd, A Tredennick, G Bucini, A Solorzano, L Prihodko, and N. P Hanan. 2010. "Does warming increase the risk of civil war in Africa?" Proceedings of the National Academy of Sciences 107 (25):E102-E102.

Theisen, O.M, H Holtermann, and H Buhaug. 2011. "Climate wars? Assessing the claim that drought breeds conflict." International Security 36 (3):79-106.

Todd Moore, Angel Scarpa, Adrian Raine. 2002. "A Meta-Analysis of Serotonin Metabolite 5-HIAA and Antisocial Behavior." Aggressive Behavior 28:299-316.

Tol, R.S.J and S Wagner. 2010. "Climate change and violent conflict in Europe over the last millennium." Climatic Change . 
Vrij, A, J Van der Steen, and L Koppelaar. 1994. "Aggression of police officers as a function of temperature: An experiment with the Fire Arms Training System." Journal of Community 83 Applied Social Psychology 4 (5):365-370.

Welch, Jarrod R., Jeffrey R. Vincent, Maximilian Auffhammer, Piedad F. Moya, Achim Dobermann, and David Dawe. 2010. "Rice yields in tropical/subtropical Asia exhibit large but opposing sensitivities to minimum and maximum temperatures." Proceedings of the National Academy of Sciences .

Wetherley, E. 2014. "Typhoons and Temperature Impact Crime Rates: Evidence from the Philippines." USF Scholarship Repository, Master's Theses (88).

Witschi, Hanspeter. 2001. "A Short History of Lung Cancer." Toxicological Sciences 64 (1):4-6.

Wooldridge, J.M. 2002. Econometric analysis of cross section and panel data. The MIT press.

Yancheva, Gergana, Norbert R Nowaczyk, Jens Mingram, Peter Dulski, Georg Schettler, Jörg F W Negendank, Jiaqi Liu, Daniel M Sigman, Larry C Peterson, and Gerald H Haug. 2007. "Influence of the intertropical convergence zone on the East Asian monsoon." Nature 445 (7123):74.

Zhang, P Brecke, H Lee, and Y He. 2007. "Global climate change, war, and population decline in recent human history." Proceedings of the National Academy of Sciences .

Zhang, D, C Jim, G Lin, Y He, J Wang, and H Lee. 2006. "Climatic change, wars and dynastic cycles in China over the last millennium." Climatic Change .

Zhang, D.D, H.F Lee, C Wang, B Li, Q Pei, J Zhang, and Y An. 2011. "The causality analysis of climate change and large-scale human crisis." Proceedings of the National Academy of Sciences 108 (42):17296-17301. 

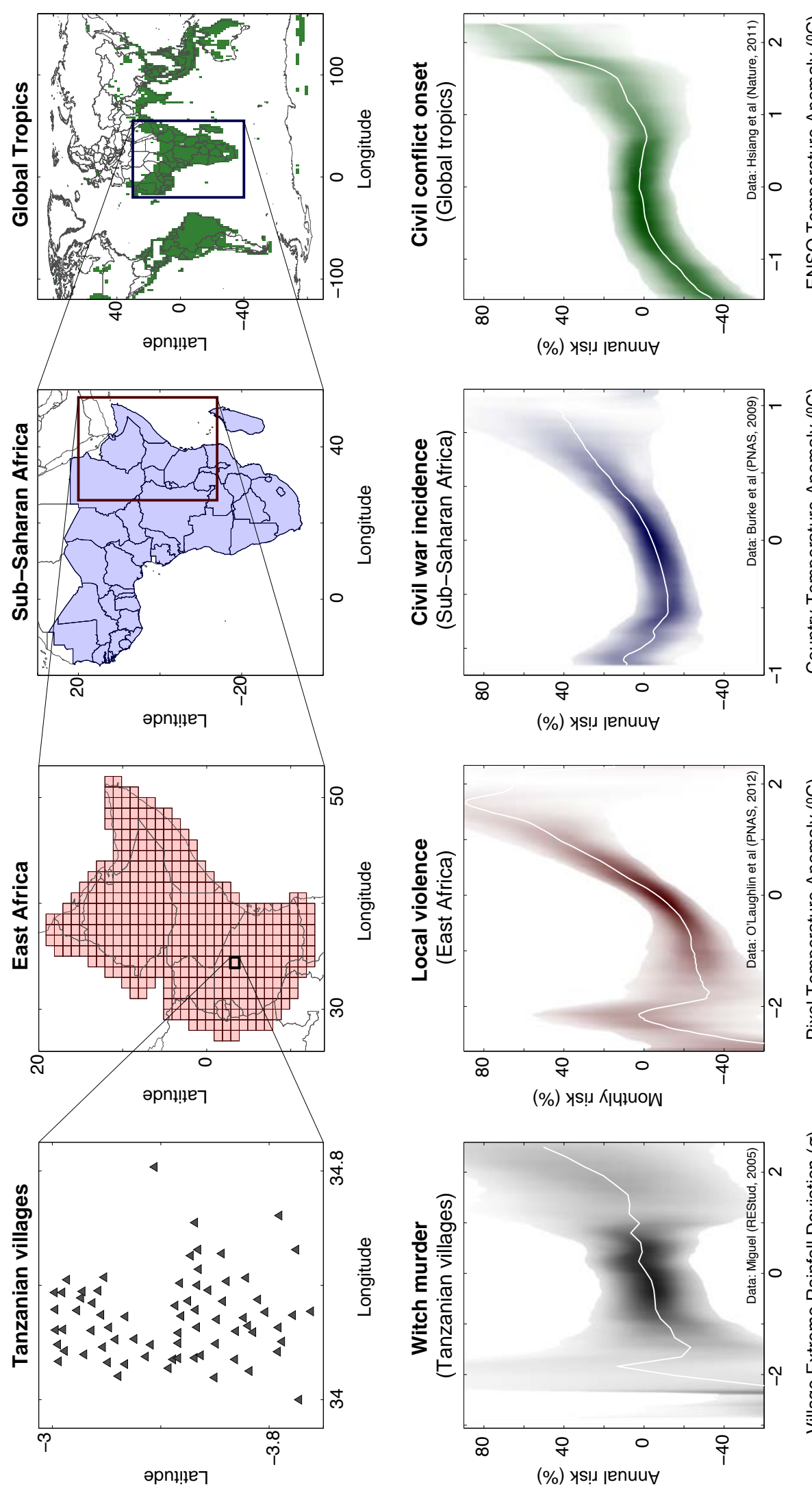

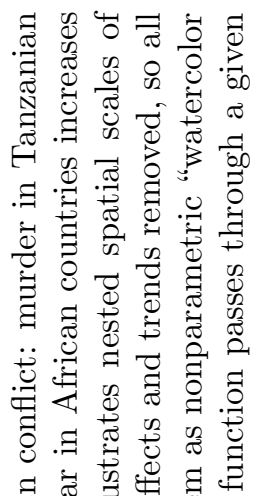

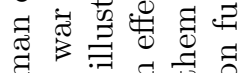

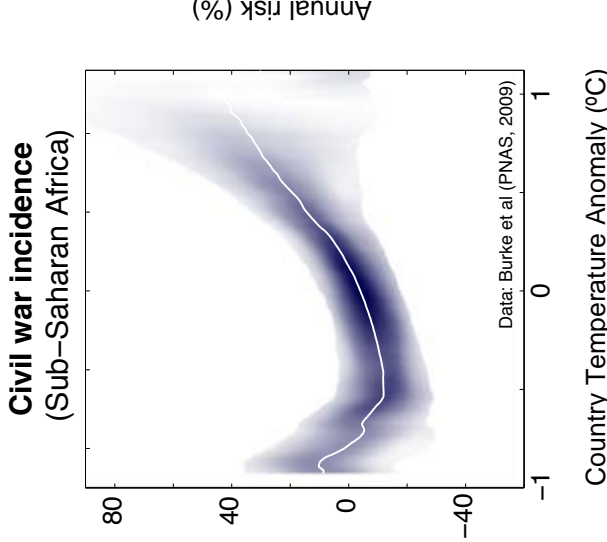

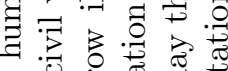

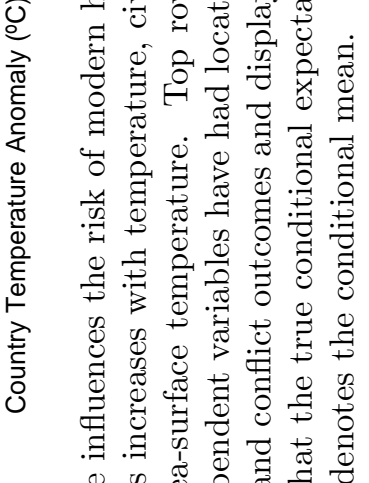
o $0 \begin{aligned} & 1 \\ & =\end{aligned}$ 芯

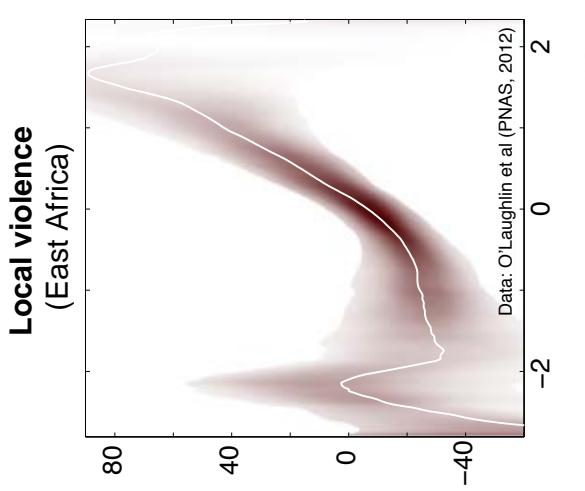

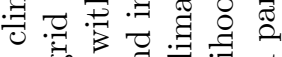

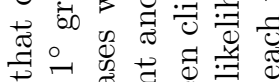
ن. 过

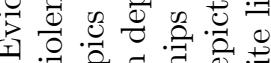
额

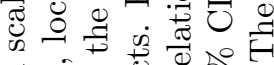

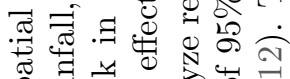

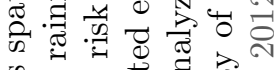

(\%) ys!ฺ Кц는

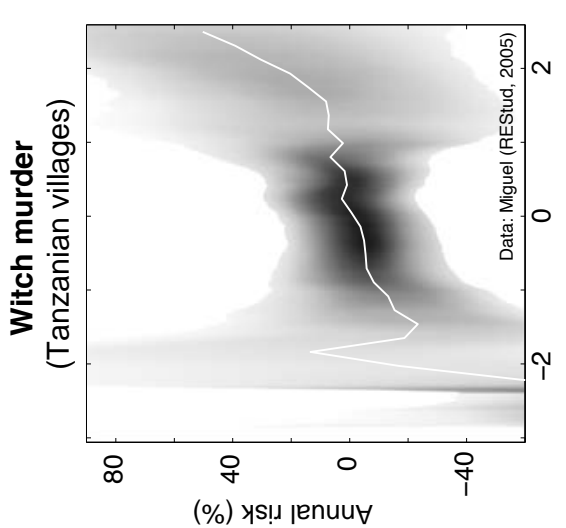

की

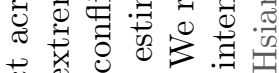

.

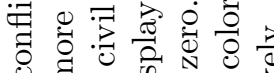

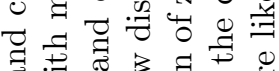

ठ

范

Ð

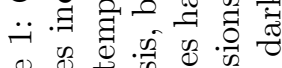

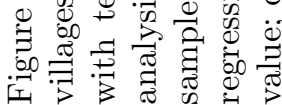




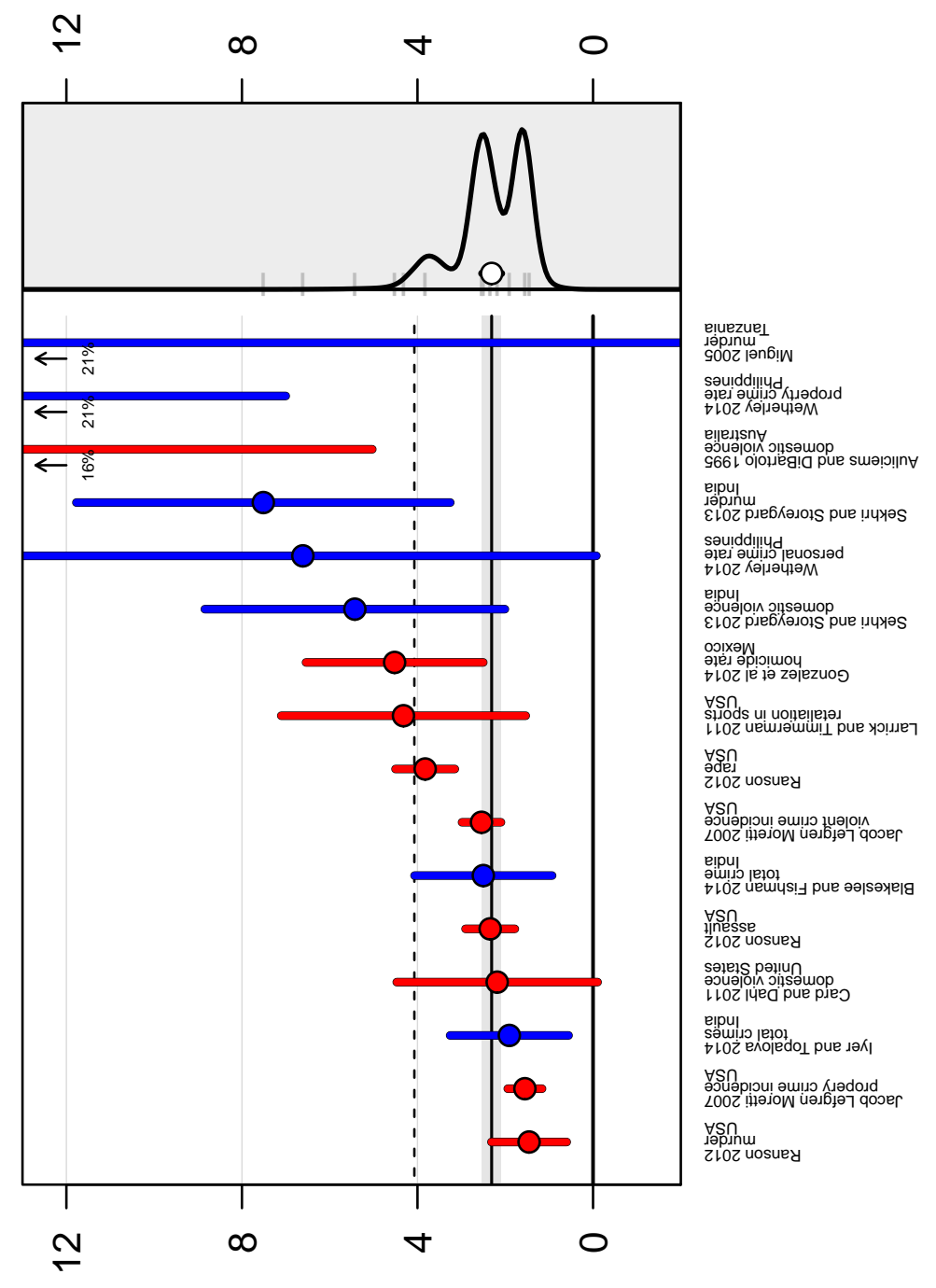

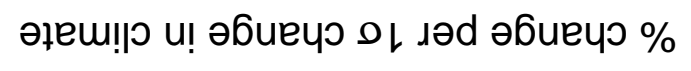

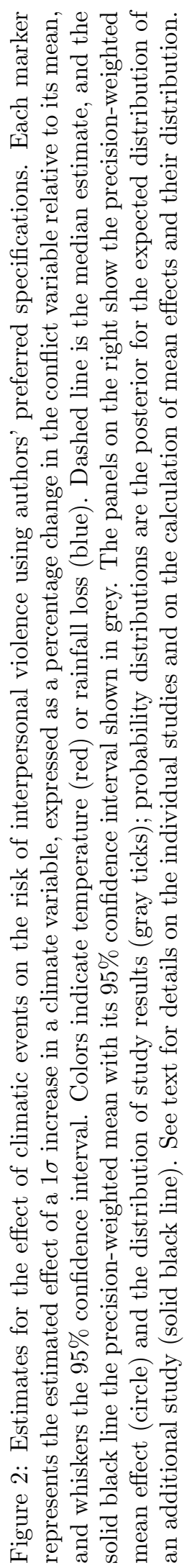




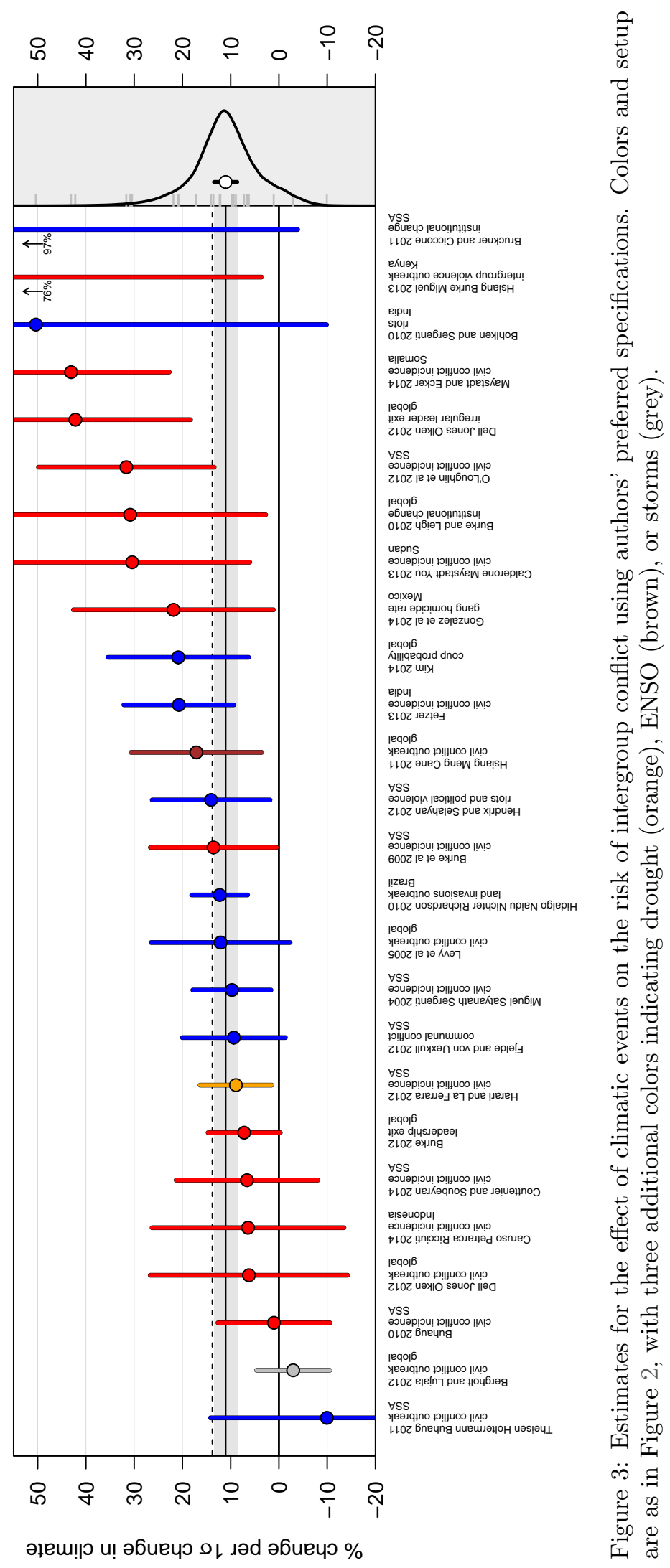



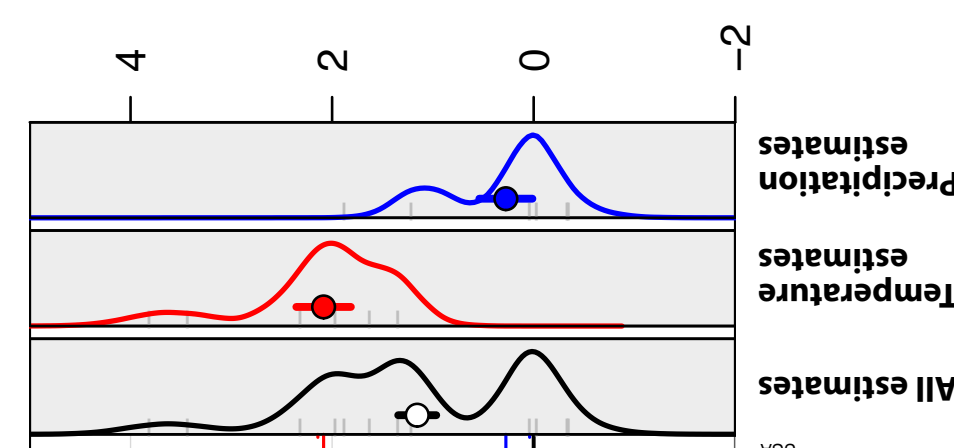

sәfeu!psə әגnłeגəduə।

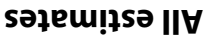

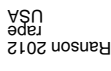

oэxan

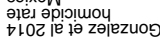

$\forall S \cap$

Itoz uosuey

$\forall$ วก

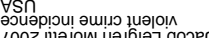

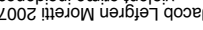

$\forall S n$
มəp

ztoz uosuey

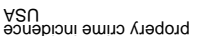

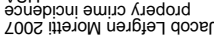

eluezue 1

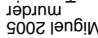

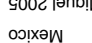

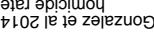

$\forall$ əรก

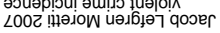

$\forall \mathrm{Sn}$

ztoz uosuey

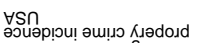

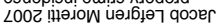

$\forall S$

ZLOZ uosuey

$\forall S \cap$
tepnn
ztoz uosuey

‡ี

$\stackrel{0}{\leftrightarrows}$

प्ठ

屯্ত

.

$\stackrel{00}{3}$ i

刍

$0 \geqslant 0$

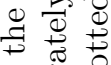

ฮี ซ

क के छ

o $=\pi$

త્વ

पै

.尹.

०ैं है

$\therefore$ 。

己

สี

$\sim$ ?

y

పె

社

$\exists \stackrel{0}{\exists}$

का वृ.

\%. \pm

( 80.

ส

正

응 를

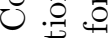

$\dot{0} \overrightarrow{0}$

苛苞

.

\&. 워

凷

00

胥高

궁

की

象

进

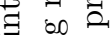

世

. $7 \cdot 5$

急焉

त्త

त)

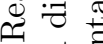

$\ddot{4}$.

४

$\exists$ 서

500 


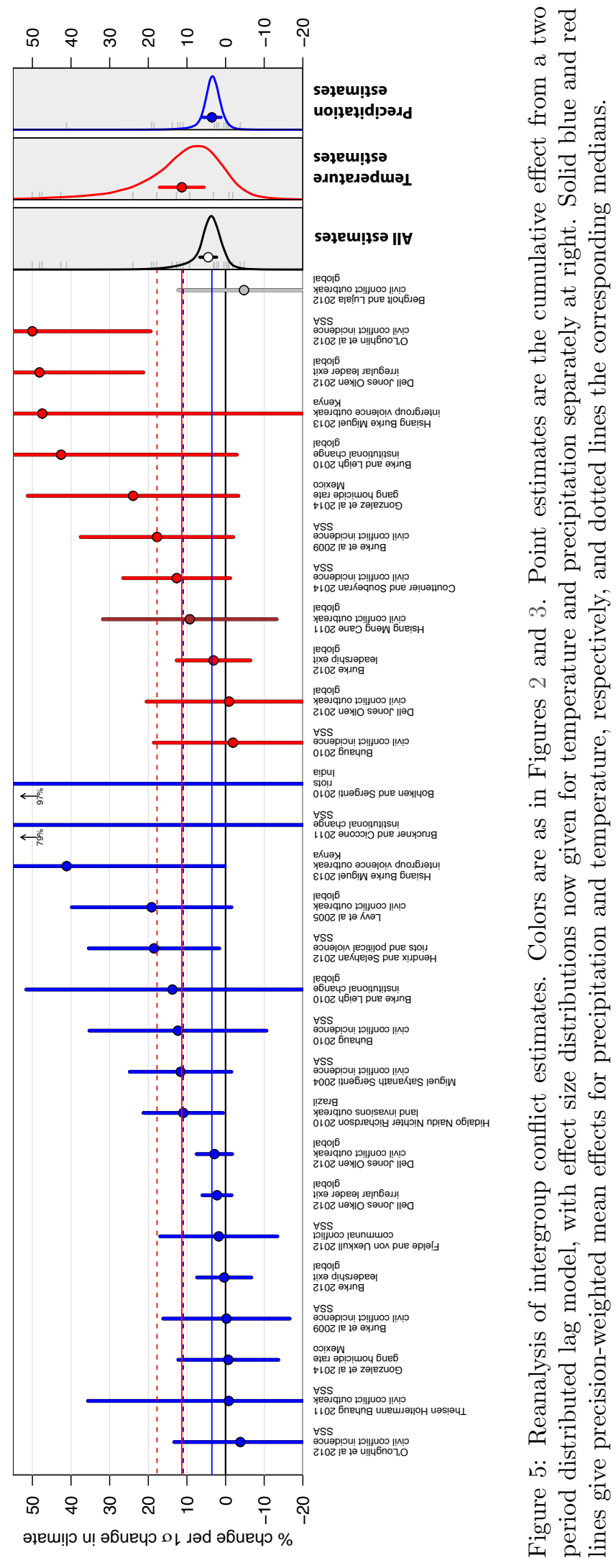



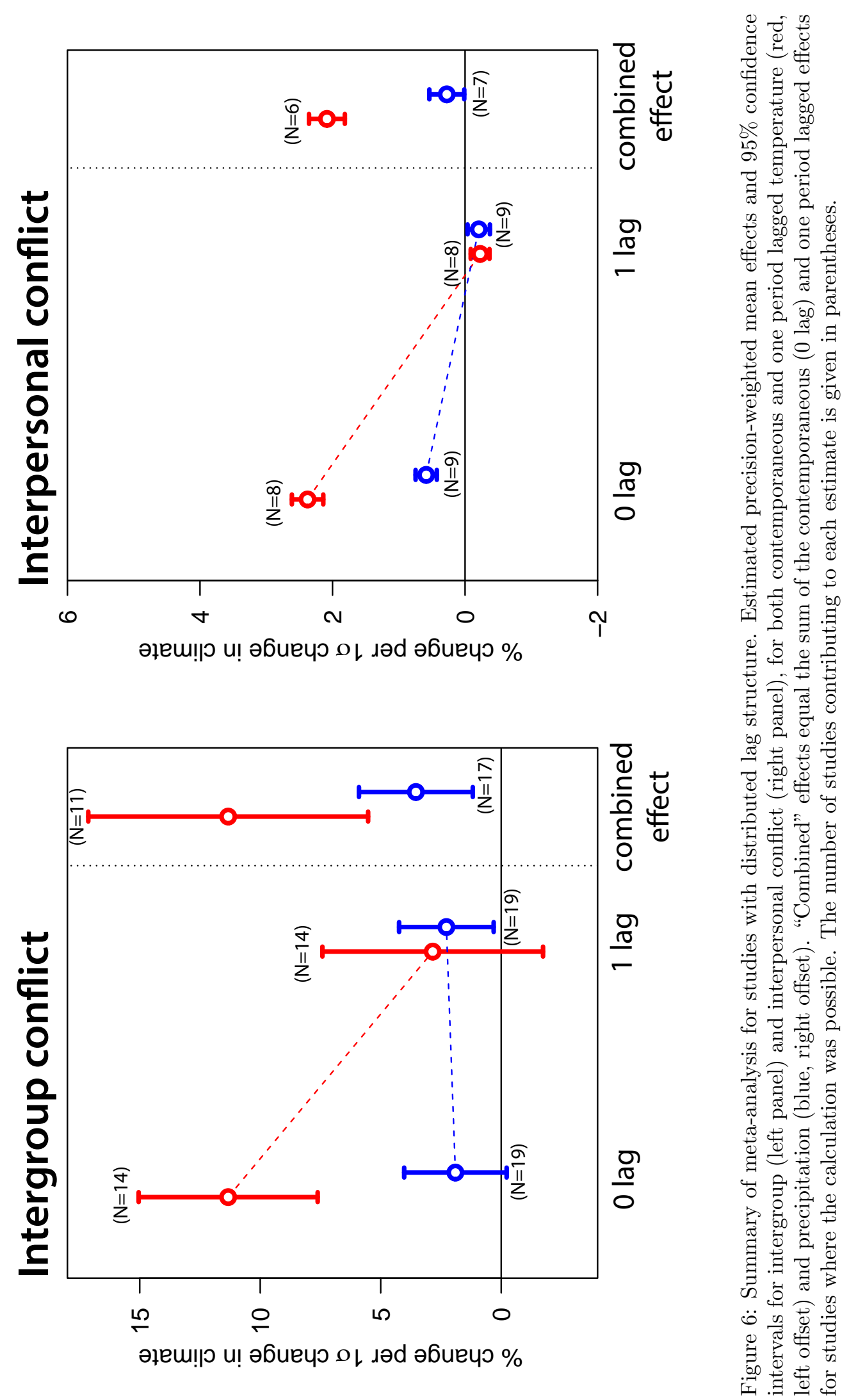


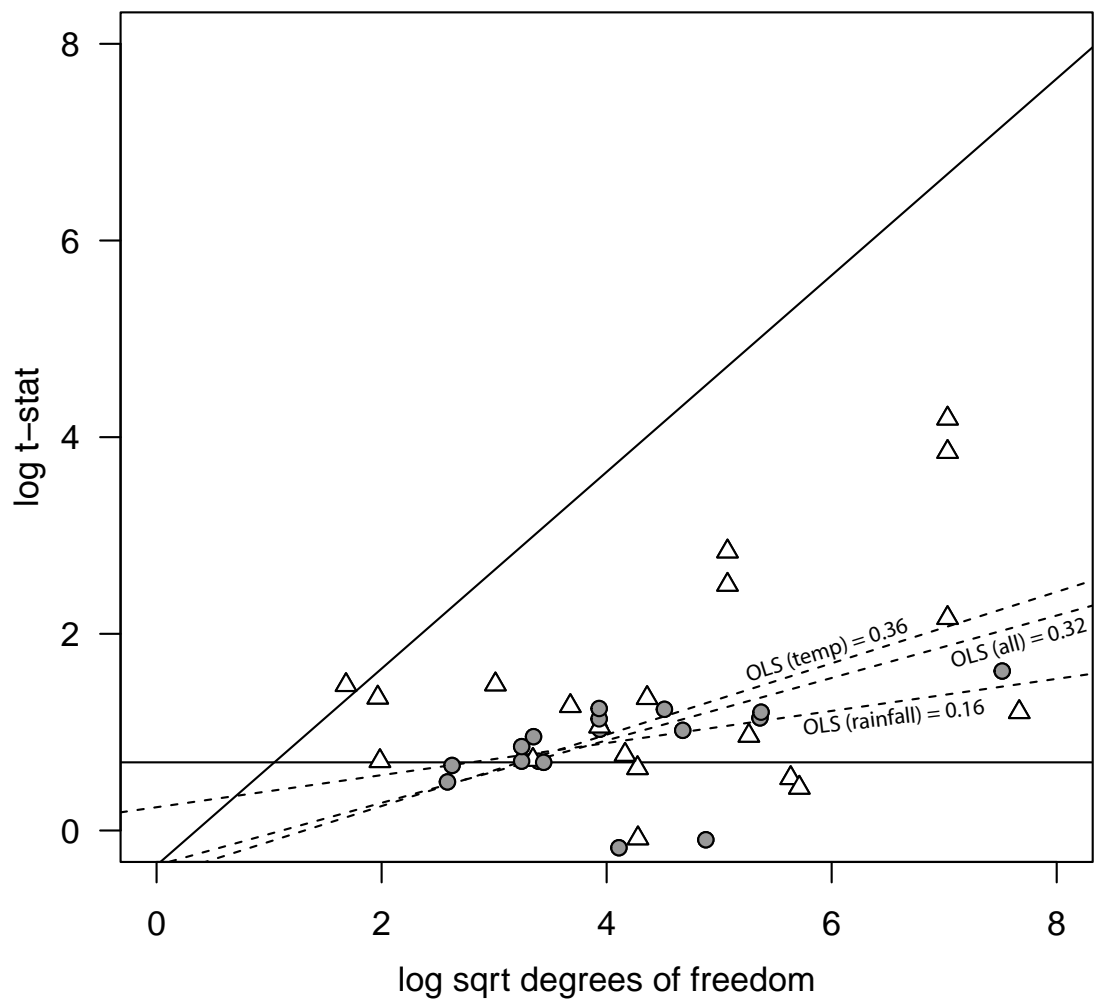

Figure 7: Relationship between log of t-statistic and log of the square root of the degreesof-freedom, using author reported t-statistics. Circles represent studies focusing on rainfall, triangles studies focusing on temperature. OLS estimates of the slope of the relationships for all estimates, temperature only estimates, and rainfall only estimates are given by the dotted lines. Solid $45^{\circ}$ line indicates the slope of 1 that theory predicts would occur in the absence of any publication bias. 


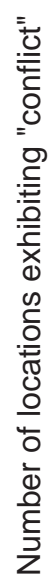
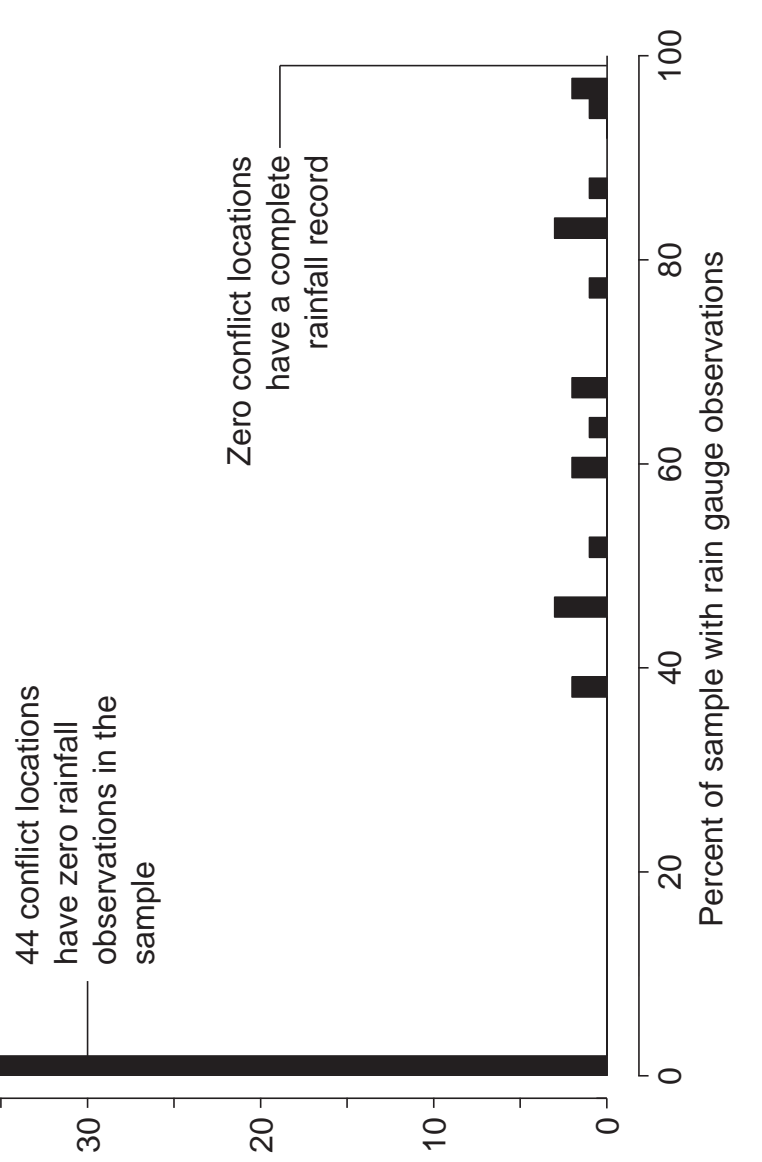

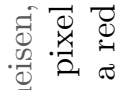

ह

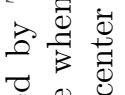

总过

范藏志

$=\overrightarrow{.}$

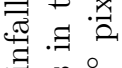

承帚栬。

प

武嵌

ङี $\approx$ శ

고의

死总.

.

仓̈

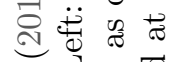

สं.

¿ 308

00.7 .7$.

粪

명 0

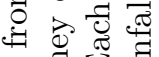

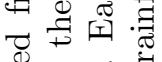

苛芯芯

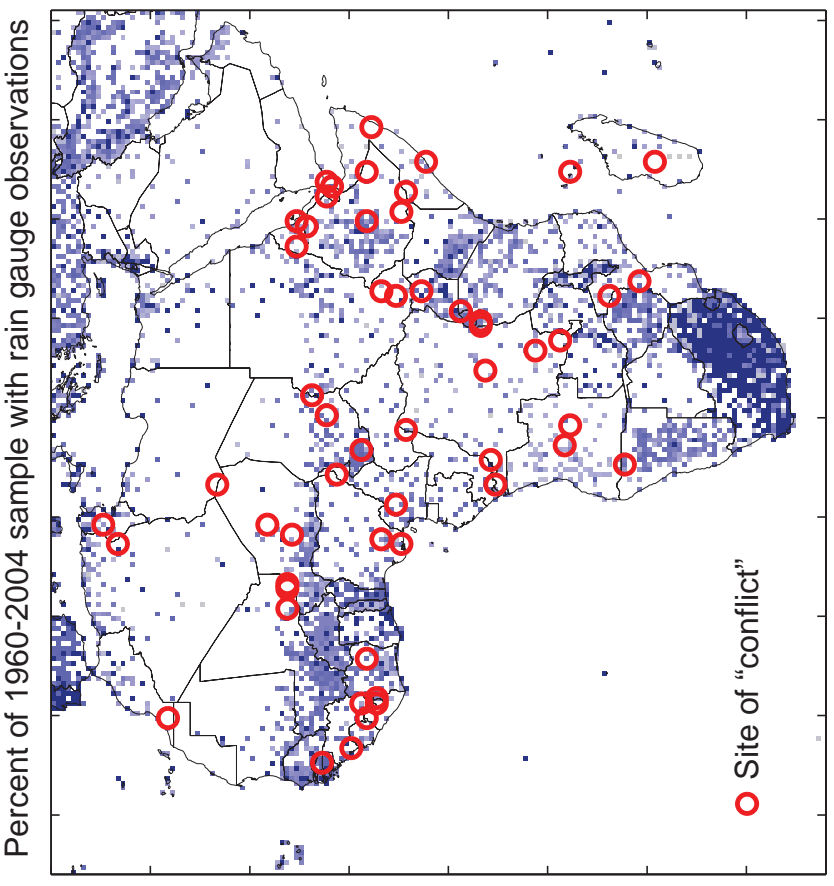

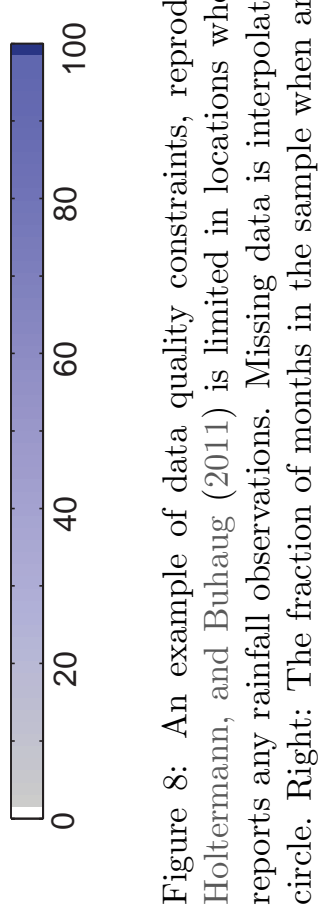




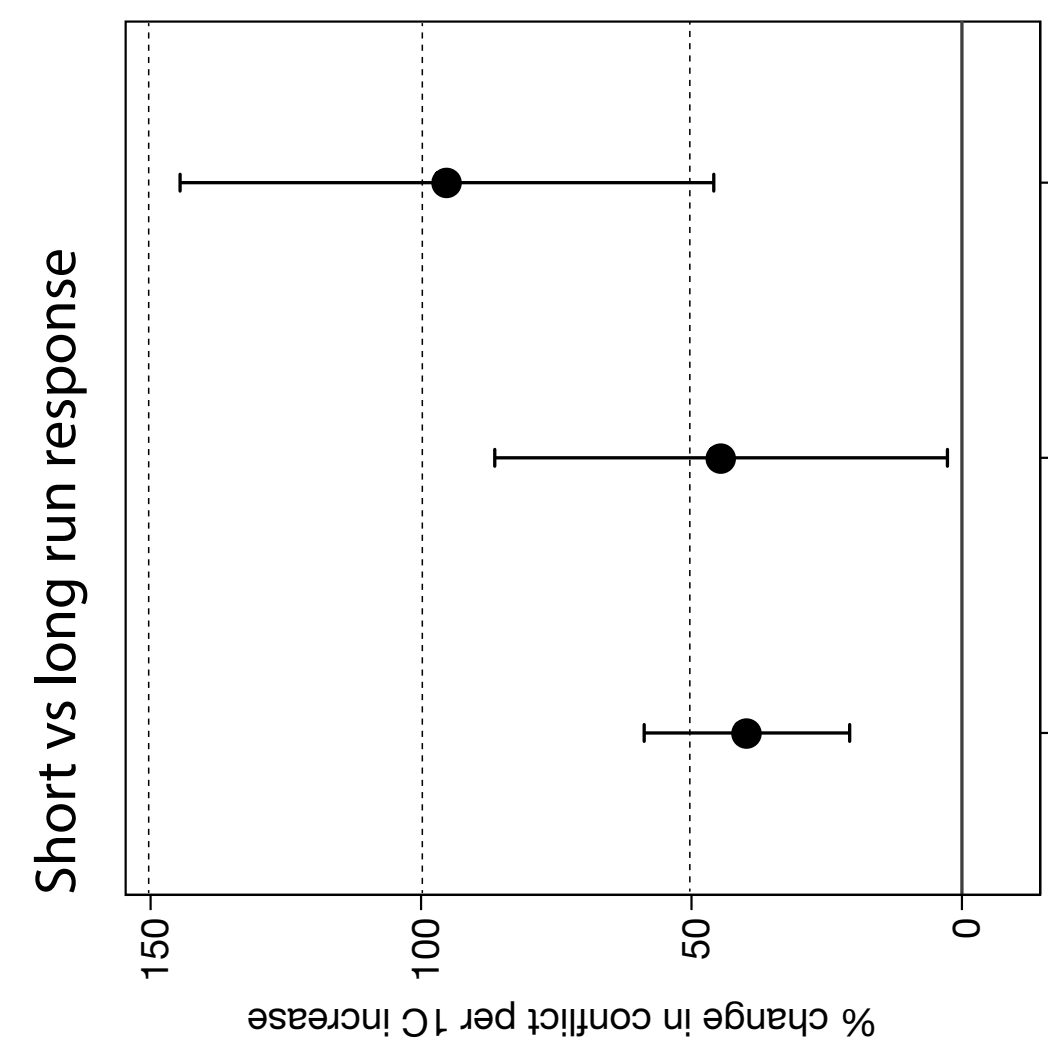

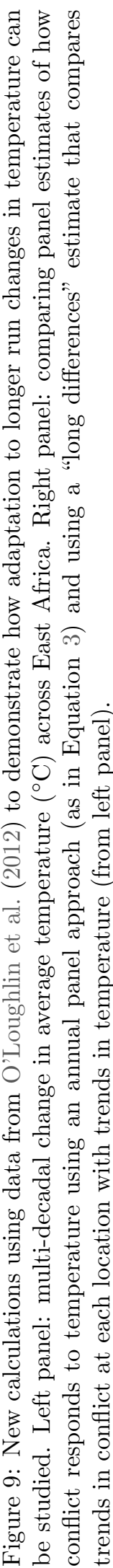

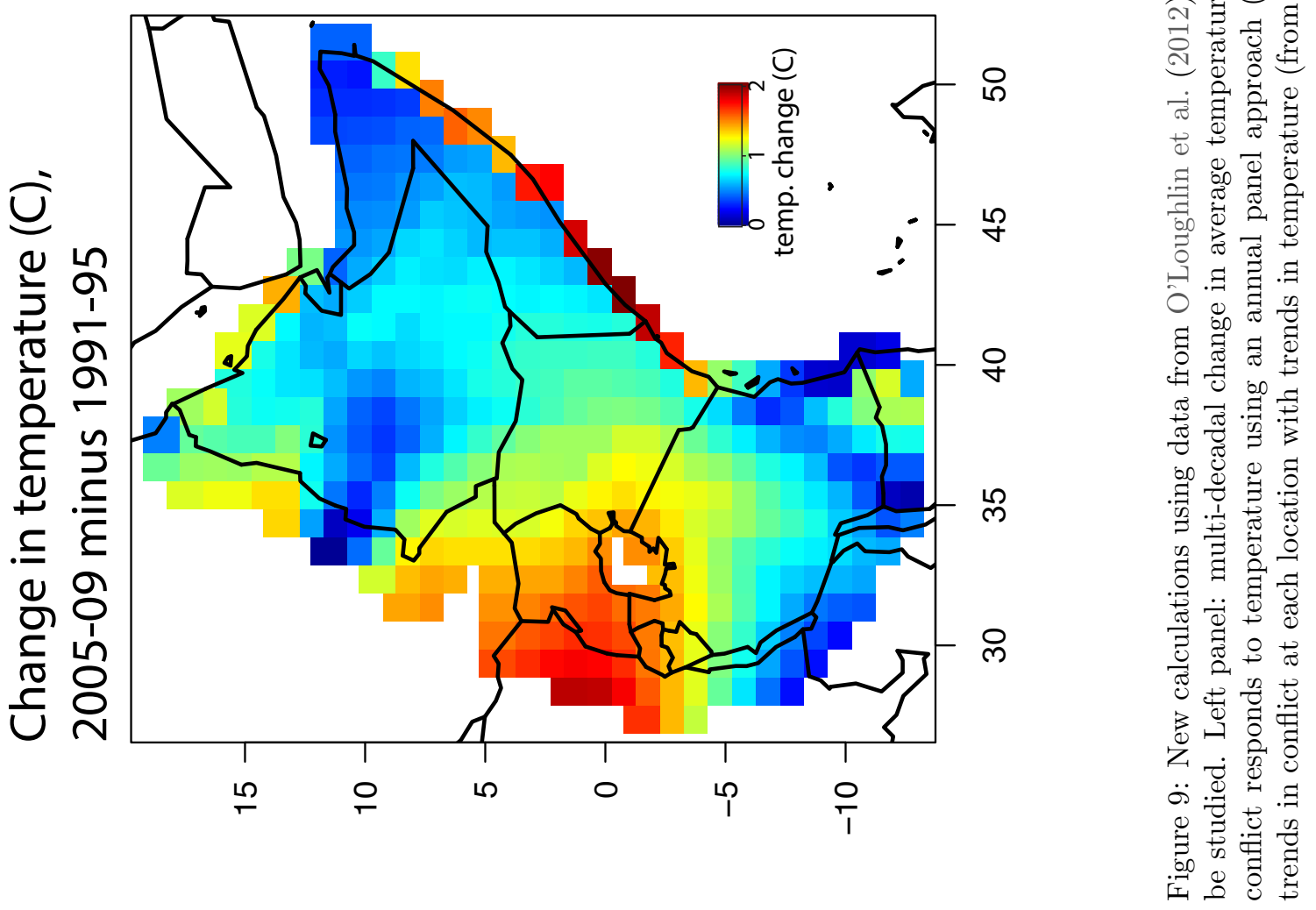




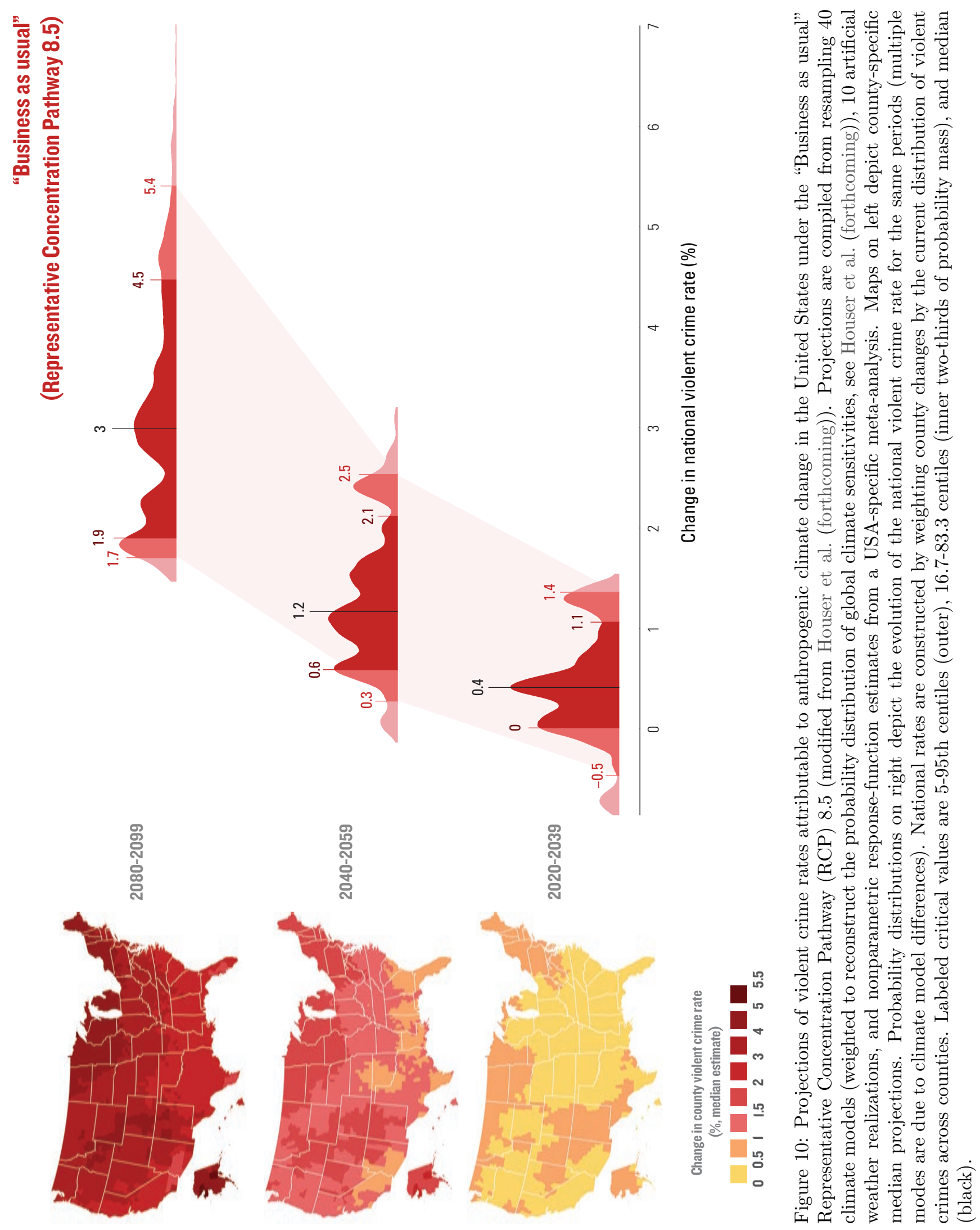




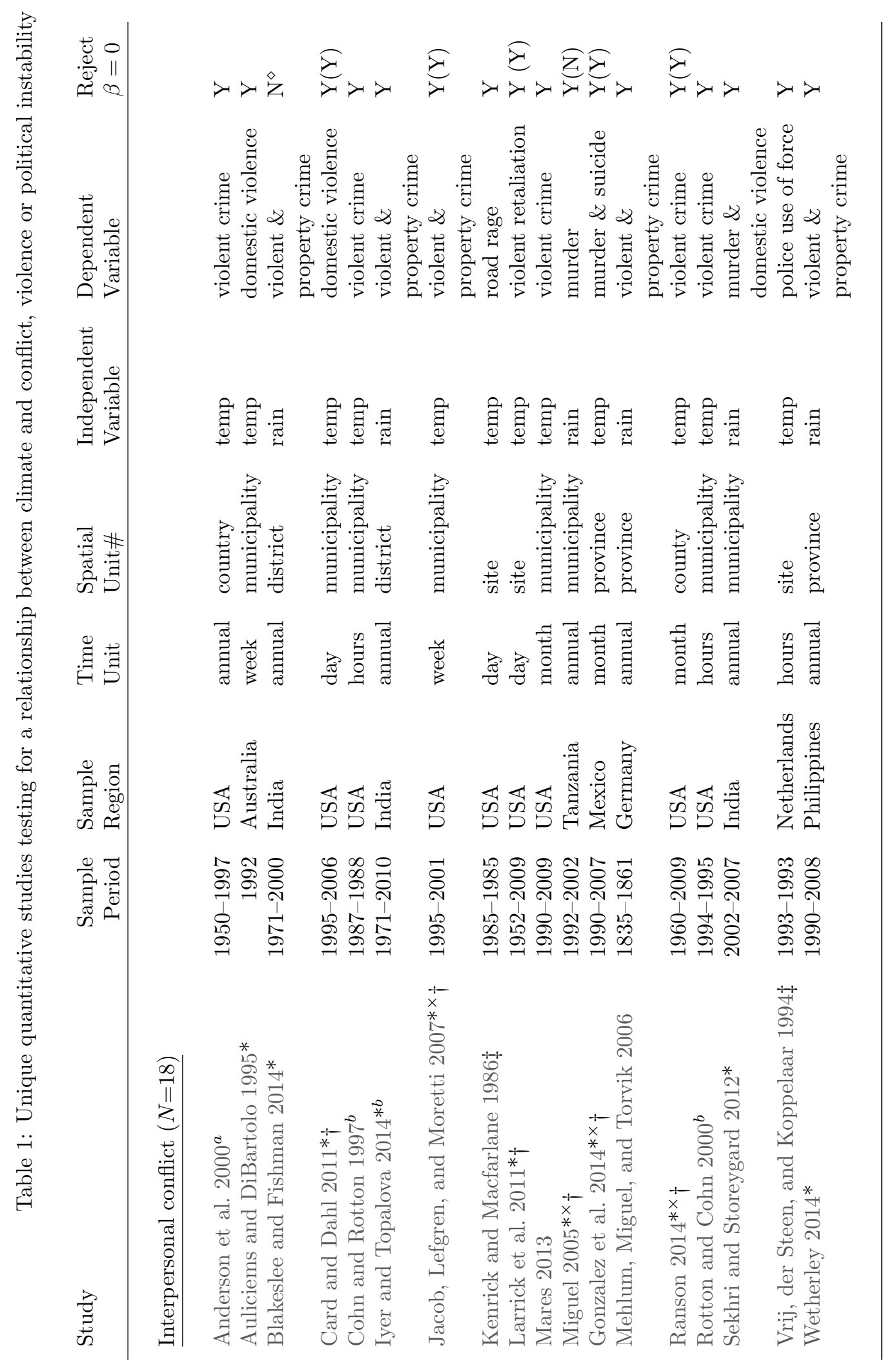




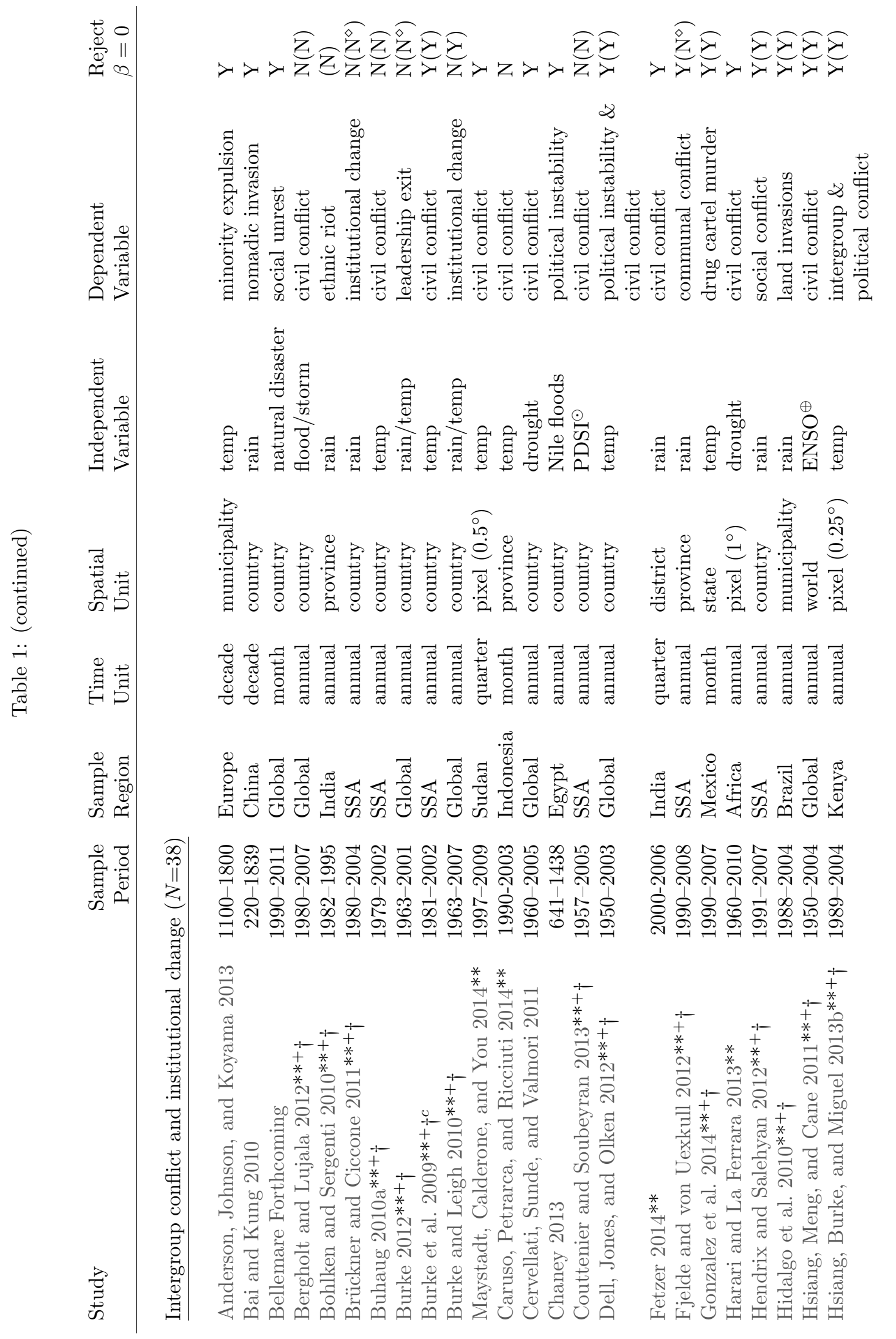




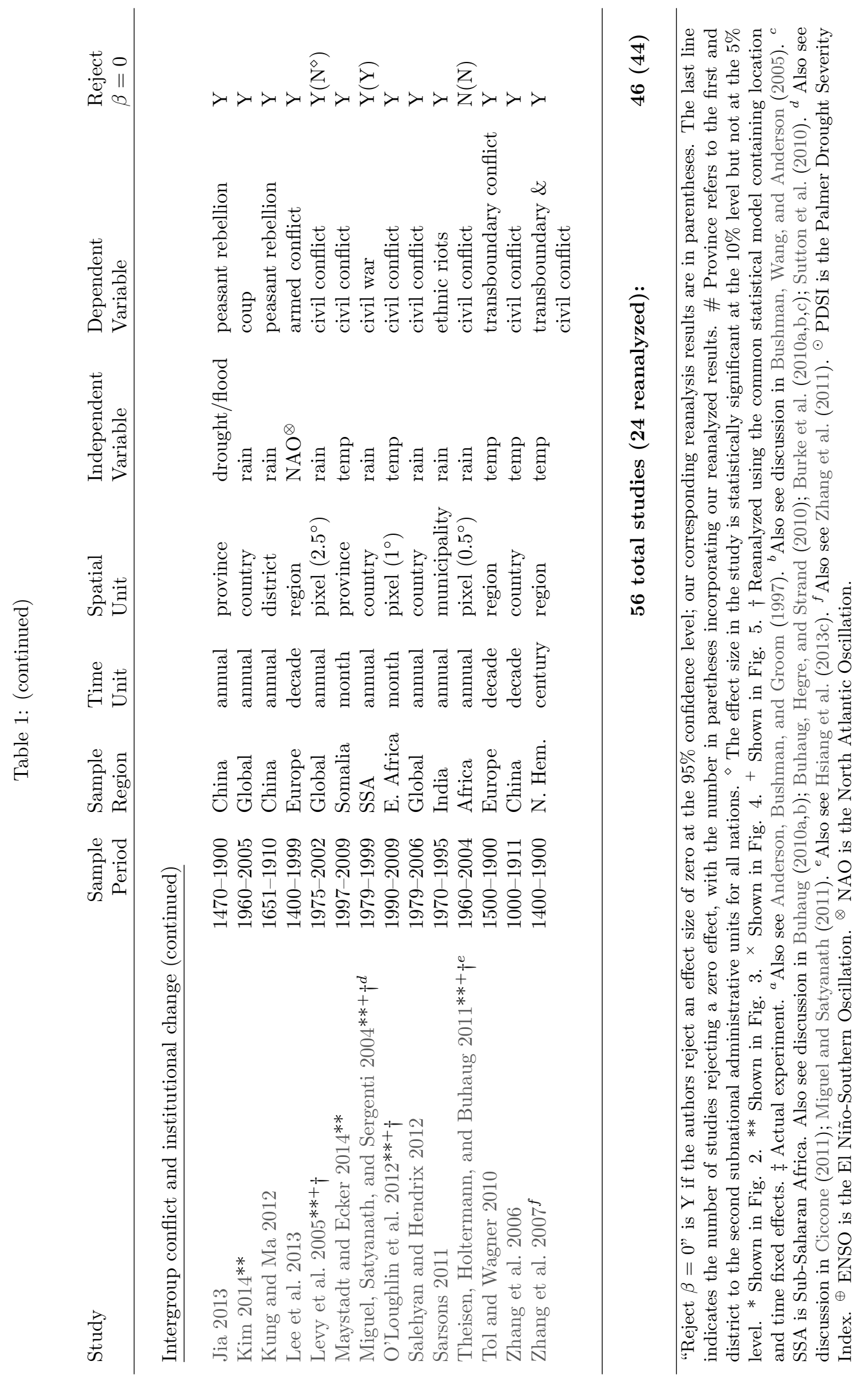


Table 2: Meta-analysis Results. "Author preferred" estimates correspond to those shown in Figures 2 and 3. All other estimates correspond to estimates from a model with both contemporaneous and lagged effects, with the "combined" estimates equalling the sum of the two effects and corresponding to the effects displayed in Figures 4 and 5; we include all studies for which it was possible to compute these estimates. The first two columns gives the precision weighted mean and its standard error for the sample of studies. The third column gives the estimated between-study standard deviation, as derived from a Bayesian hierarchical model. The last column gives the number of studies used in each estimate.

\begin{tabular}{|c|c|c|c|c|c|}
\hline Effect Type & Median & $\begin{array}{c}\text { Mean } \\
\mu\end{array}$ & $\begin{array}{l}\text { Standard Error } \\
\qquad \mathrm{SE}(\mu)\end{array}$ & $\begin{array}{c}\text { Cross-Study Std. Dev } \\
\tau\end{array}$ & $\mathrm{N}$ \\
\hline \multicolumn{6}{|l|}{ Intergroup conflict } \\
\hline Author preferred & 13.81 & 11.04 & 1.22 & 8.46 & 26 \\
\hline Temperature, contemporaneous & 14.75 & 11.33 & 1.90 & 6.29 & 14 \\
\hline Temperature, lagged & 7.85 & 2.84 & 2.34 & 10.64 & 14 \\
\hline Temperature, combined & 17.74 & 11.33 & 2.96 & 14.44 & 11 \\
\hline Precipitation, contemporaneous & 1.90 & 1.90 & 1.08 & 3.84 & 19 \\
\hline Precipitation, lagged & 4.24 & 2.28 & 1.00 & 2.09 & 19 \\
\hline Precipitation, combined & 10.95 & 3.54 & 1.20 & 3.05 & 17 \\
\hline \multicolumn{6}{|l|}{ Interpersonal conflict } \\
\hline Author preferred & 4.07 & 2.31 & 0.11 & 1.35 & 16 \\
\hline Temperature, contemporaneous & 3.37 & 2.38 & 0.12 & 1.83 & 8 \\
\hline Temperature, lagged & -0.20 & -0.23 & 0.07 & 0.52 & 8 \\
\hline Temperature, combined & 2.14 & 2.08 & 0.14 & 1.26 & 6 \\
\hline Precipitation, contemporaneous & 1.16 & 0.59 & 0.08 & 0.78 & 9 \\
\hline Precipitation, lagged & 0.01 & -0.21 & 0.09 & 0.31 & 9 \\
\hline Precipitation, combined & 0.04 & 0.28 & 0.13 & 0.91 & 7 \\
\hline
\end{tabular}

